\title{
Genetic interaction between hoxb-5 and hoxb-6 is revealed by nonallelic noncomplementation
}

\author{
Derrick E. Rancourt, Teruhisa Tsuzuki, ${ }^{1}$ and Mario R. Capecchi ${ }^{2}$ \\ Howard Hughes Medical Institute, Department of Human Genetics \\ University of Utah School of Medicine, Salt Lake City, Utah 84112 USA
}

\begin{abstract}
hoxb-5 and hoxb-6 are adjacent genes in the mouse HoxB locus and are members of the homeotic transcription factor complex that governs establishment of the mammalian body plan. To determine the roles of these genes during development, we generated mice with a targeted disruption in each gene. Three phenotypes affecting brachiocervicothoracic structures were found in the mutant mice. First, hoxb-5 homozygotes have a rostral shift of the shoulder girdle, analogous to what is seen in the human Sprengel anomaly. This suggests a role for hoxb-5 in specifying the position of limbs along the anteroposterior axis of the vertebrate body. Second, hoxb $-6^{-}$homozygotes frequently have a missing first rib and a bifid second rib. The third phenotype, an anteriorizing homeotic transformation of the cervicothoracic vertebrae from $\mathrm{C6}$ through $\mathrm{T1}$, is common to both hoxb-5 and hoxb-6 homozygotes. Quite unexpectedly, hoxb-5, hoxb-6 transheterozygotes (hoxb-5 $-5^{-}$hox $b-6^{+} / h_{0 \times} b-5^{+}$hoxb- $\left.6^{-}\right)$also show the third phenotype. By this classical genetic complementation test, these two mutations appear as alleles of the same gene. This phenomenon is termed nonallelic noncomplementation and suggests that these two genes function together to specify this region of the mammalian vertebral column.
\end{abstract}

[Key Words: Gene targeting; Hox genes; nonallelic noncomplementation; cervicothoracic vertebrae; forelimbs; homeotic transformations]

Received October 21, 1994; revised version accepted November 17, 1994.

Genetic analysis of Drosophila has revealed a hierarchy of genes that regulate embryonic development. A critical position in this hierarchy is occupied by the homeotic gene complex $(\mathrm{HomC})$, which encodes eight transcription factors that share a common DNA-binding motif known as the homeo domain (Kissinger et al. 1990; Otting et al. 1990). In Drosophila, these genes act as master switches, governing the formation of parasegmental identity through the activation and/or repression of downstream effector genes (Akam 1987). Mutations in these genes result in changes of parasegmental identity (Lewis 1978).

In mammals, the homeotic complex (Hox) is a multigene family composed of 38 genes organized as four linkage groups on four separate chromosomes. These tandem arrays (designated $\operatorname{Hox} A, \operatorname{Hox} B, \operatorname{Hox} C$, and $\operatorname{Hox} D$ ) bear remarkable structural similarity to HomC (Scott 1992). In the mouse, as in Drosophila, the chromosomal order of the homeotic genes reflects the relative position of Hox gene expression along the anteroposterior $(\mathrm{A} / \mathrm{P})$ axis of the developing embryo (Duboule and Dollé 1989; Gra-

'Present address: Department of Biochemistry, Medical Institute of Bioregulation, Kyushu University, Higashi-Ku, Fukuoka City 812, Japan.

${ }^{2}$ Corresponding author. ham et al. 1989). By analogy, the Hox genes are also thought to act as master switches specifying regional information along the $\mathrm{A} / \mathrm{P}$ axis during mammalian embryogenesis.

Based on DNA sequence similarities, the genes in each Hox cluster have been aligned into 13 subfamilies or paralogous groups (Scott 1992). Each paralogous group contains at least two members from separate linkage groups. The $\operatorname{Hox} B$ locus, which most closely resembles Hom $C$ organization, has only the first nine paralogous groups. Within the $\operatorname{Hox} A, \operatorname{Hox} C$, and $\operatorname{Hox} D$ clusters, four more paralogous groups have been described, presumably derived through the duplication of the ancestral $A b d-B$ gene (Kappen et al. 1989; Garcia-Fernandez and Holland 1994).

The similarities in both the structure and expression patterns among genes of the same paralogous group have led to the hypothesis that paralogous Hox genes perform overlapping functions and that $A / P$ regional identity may be dictated by the combination of Hox genes expressed within a given region (Hunt et al. 1991; Holland et al. 1992). Targeted mutations in numerous mouse Hox genes have resulted in regionally restricted defects occurring at or near the gene's anterior expression boundary (Chisaka and Capecchi 1991; Lufkin et al. 1991; 
Chisaka et al. 1992; LeMouellic et al. 1992; Carpenter et al. 1993; Condie and Capecchi 1993; Mark et al. 1993; Dollé et al. 1993; Gendron-Maguire et al. 1993; Jeannotte et al. 1993; Ramirez-Solis et al. 1993; Rijli et al. 1993; Small and Potter 1993; Condie and Capecchi 1994; Davis and Capecchi 1994; Kostic and Capecchi 1994). In many cases, as seen in Drosophila, loss of a specific Hox gene results in a respecification of a structure to a more anterior or posterior fate. This has been demonstrated most clearly in mutants that exhibit transformations of the vertebral column.

The role of Hox genes in the vertebrate body plan, however, is more complex than in insects, functioning in regions where overt segmentation is not apparent (Dollé et al. 1993; Small and Potter 1993; Davis and Capecchi 1994). Expansion of the homeotic complex in vertebrates, therefore, may have permitted the diversification and specialization of various members of the complex, while at the same time increasing the potential for genetic redundancy. Analysis of the genetic interactions between Hox genes has just begun. For example, mice mutant for both hoxa-3 and hoxd-3 show that these two paralogous genes interact strongly and quantitatively (Condie and Capecchi 1994). Although mice mutant for the individual genes show no overlap in phenotype (Chisaka and Capecchi 1991; Condie and Capecchi 1993), mice mutant for both genes show a dosage dependent exacerbation of the phenotypes present in each mutant.

Here, we describe the interactions between two adjacent Hox genes within the same linkage group. Targeted disruption of hoxb-5 and hoxb-6 results in several defects that are confined to the mesodermally derived, brachiocervicothoracic structures. Mice heterozygous for either the hoxb-5 or hoxb-6 mutation show no mutant phenotype. Mice homozygous for the hox $b-5^{-}$or hoxb$6^{-}$disruption each show two phenotypes, one that is unique to the hox $b-5^{-}$or hoxb- $6^{-}$mutation and the other that is observed in both hoxb-5- and hoxb- $6^{-}$homozygotes. hox $b-5^{-} /$hox $b-5^{-}$mice have an anterior displacement of the shoulder girdle relative to the vertebral column. hox b-6- / hoxb-6 $-6^{-}$mice display first and second rib defects. Both hoxb $-5^{-}$and hoxb-6 homozygotes show anteriorizing homeotic transformations of cervicothoracic vertebrae C6 through T1. Surprisingly, transheterozygotes (hox b-5 $-5^{-}$hox $b-6^{+} /$hox $b-5^{+}$hox $b-6^{-}$) also display the cervicothoracic abnormality. Such nonallelic noncomplementation between these two heterozygous mutations is most readily, though not exclusively, explained if the products of the two genes function as a complex.

\section{Results}

Targeted disruption of the hoxb- 6 and hoxb-5 genes

Figure 1A shows the targeting vectors pB6neo2TK and pB5neo2TK that were used to disrupt the hoxb-6 and hox $b-5$ genes, respectively, via homologous recombination (Capecchi 1989, 1994). pB6neo2TK contains $10.1 \mathrm{~kb}$ of mouse genomic DNA encompassing the hoxb-6 gene, with a neomycin resistance $\left(n e o^{r}\right)$ gene derived from pKT3NP4 (Deng et al. 1993) inserted into the coding sequence of the first exon. Similarly, pB5neo2TK contains $8.9 \mathrm{~kb}$ of mouse genomic DNA encompassing the hox $b-5$ gene, with the neo ${ }^{\mathrm{r}}$ gene from pMC1neopA (Thomas and Capecchi 1987) inserted into the coding sequence of the first exon (Krumlauf et al. 1987). Flanking the mouse sequences in both targeting vectors are the thymidine kinase genes (TK1, TK2) of herpes simplex virus type I and type II (HSV-1 and HSV-2, respectively). Both $\mathrm{pB} 6 \mathrm{neo} 2 \mathrm{TK}$ and $\mathrm{pB} 5 \mathrm{neo} 2 \mathrm{TK}$ were introduced individually into CCl.2 embryonic stem (ES) cells by electroporation. Cells that had undergone a gene targeting event were enriched by positive-negative selection (Mansour et al. 1988) and identified by Southern blot analysis using flanking hybridization probes. These cell lines were analyzed with additional restriction enzymes and probes to confirm the integrity of the targeted locus on both sides of the neo insertion. Representative Southern blots of the DNA from targeted cell lines that were used to generate germ-line chimeras for hoxb-6 and hoxb-5 are shown in Figure 1, B and D, respectively. Cells from both clones were injected into $\mathrm{C} 57 \mathrm{Bl} / 6 \mathrm{~J}$ blastocysts to generate germ-line chimeras.

Mice heterozygous for either the hox $b-6^{-}$or hox $b-5^{-}$ mutations were interbred to generate homozygotes. Southern blots were used to genotype the offspring of the hox $b-6^{-}$and hoxb $-5^{-}$pedigrees, respectively (Fig. 1C,E). Heterozygous intercrosses of either Hox gene mutation gave rise to the expected Mendelian genotype ratio at weaning. Mice of both sexes homozygous for either the hoxb-5 or hoxb-6 mutation are viable and fertile.

\section{Forelimbs are shifted anteriorly in hoxb-5 homozygotes}

hox $b-5^{-}$mutant animals show malformations of both the axial and appendicular skeletons. The forelimbs of hox $b-5^{-}$homozygotes are shifted anteriorly relative to the axial skeleton (Fig. 2). This results in a V-shaped shoulder girdle in homozygous mutants (Fig. 2B) compared with heterozygous (Fig. 2A) or wild-type mice (not shown). Occasionally this shift was unilateral (Fig. 2C). Lateral views of these mutant animals demonstrate that the forelimbs are shifted anteriorly by the distance of one and sometimes two cervical vertebrae, with the rostral edge of the scapula aligning with the fourth or third cervical vertebrae instead of the fifth (not shown).

The bones of the shoulder girdle appear normal in hox $b-5^{-}$homozygotes, suggesting that this phenotype results from a change in the position of the shoulder relative to the axial skeleton. Such an alteration could occur early in development, when the position of the forelimb is specified, or could be attributable to a later defect in the formation of the musculature. To examine the position of the developing limb in hoxb-5- embryos prior to the elaboration of the musculature, embryonic day 13.5 (E13.5) embryos were eviscerated and stained for both nerve tissue and cartilage. hoxb $-5^{-}$homozy- 
Figure 1. hoxb-6 and hoxb-5 targeting and genotypic analysis. $(A)$ Structure of the replacement targeting vectors pB6neo2TK and pB5neo2TK. EcoRI (E), BamHI (B), Hin$\mathrm{dIII}(\mathrm{H}), \mathrm{XbaI}(\mathrm{Xb})$, and $\mathrm{XhoI}(\mathrm{Xh})$ restriction sites within each targeting vector are indicated. First and second exons of each gene are represented by solid boxes. The $5^{\prime} \rightarrow 3^{\prime}$ orientation of the hoxb-6, hoxb-5, neopA (neor), HSV-1 TK (TK1), and HSV-2 TK (TK2) genes is left to right. $(B, D)$ Southern blot analysis of hoxb-6 $(B)$ and hoxb-5 $(D)$ targeted ES cells. $(B)$ Genomic DNA from the parental cell line, CCI.2 (ES) and the hoxb-6 targeted cell line (B6), was digested with SalI-XhoI (left) or XbaI (right). (D) Genomic DNA from the parental cell line, CC1.2 (ES), and the hoxb-5 targeted cell line (B5), was digested with BamHI (left) and EcoRI (right). The left panel $B$ was hybridized with a $2.5-\mathrm{kb}$ EcoRI-BamHI fragment (Fig. 1F, probe A) lying immediately $5^{\prime}$ to genomic sequences used in the pB6neo2TK targeting vector. The hybridizing fragment that shifts down from 18.0 to $13.0 \mathrm{~kb}$ represents the disrupted hoxb-6 $6^{-}$ allele in cell line $2 \mathrm{c} 6$. The left panel of $D$ was hybridized with a $0.9-\mathrm{kb}$ HindIIISau3A fragment (Fig. 1F, probe C) lying 3' to genomic sequences used in the pB5neo2TK targeting vector. The hybridizing fragment that shifts up from 12.0 to $13.1 \mathrm{~kb}$ indicates the disrupted hoxb $-5^{-}$allele. The right panels of both $B$ and $D$ were hybridized with an internal 1.5 -kb BamHI fragment (Fig. 1F, probe B). The hybridizing fragments that shift up from 6.5 to $8.2 \mathrm{~kb}$ $(B)$ and shift down from 4.8 to $3.8 \mathrm{~kb}(D)$ represent the hoxb-6- $6^{-}$and hox $b-5^{-}$alleles, respectively. $(C, E)$ Southern blot analysis of

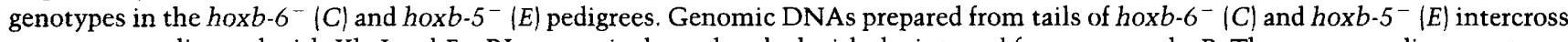
progeny were digested with $X b a \mathrm{I}$ and $E c o R I$, respectively, and probed with the internal fragment, probe B. The corresponding genotypes are indicated at the top of each gel. (F) Diagram of the hoxb-6-hoxb-5 region in CC1.2 (ES) cells, and in hoxb-6 (B6) and hoxb-5 (B5) targeted cells. The bars represent restriction fragments generated from the Southern analysis in $B-E$. Probes used in genomic DNA analysis (probes $\mathrm{A}, \mathrm{B}$, and $\mathrm{C}$ ) are indicated.

gotes with anteriorly shifted forelimbs could be observed as early as day 13.5 of embryogenesis (Fig. 3B). Of 13 homozygous mutant embryos, 10 animals clearly showed that the position of the limbs was shifted relative to the vertebral column, and in all cases but one, the shifts were bilateral. No shifts were observed in 12 heterozygous controls (Fig. 3A). One consequence of the shift is that the brachial plexus enters the forelimb at a more posterior position. This more posterior articulation of the brachial plexus was also observed using a second method to characterize the anterior shift of the developing limb. The nerves of the brachial plexus were labeled by injection of fluorescent carbocyanine dye into the cervical nerves of E12.5 embryos. In hoxb-5- homozygotes, the nerves of the brachial plexus enter the forelimb at a more caudal position than in heterozygous controls (Fig.
3, D and C, respectively|, where entry occurs at the midpoint of the limb. The relative trajectories of the nerves are similar in both animals, consistent with the interpretation that the limb bud is shifted rostrally in homozygous mutant embryos. This shift was observed bilaterally in seven of seven homozygotes, whereas no shift was observed in six of six heterozygous controls.

\section{Ribs and intercostal nerves are altered in hoxb- $6^{-}$ mutant mice}

Skeletal staining of hoxb-6- homozygous mutant animals revealed both costal malformations and defects of the axial skeleton. Homozygous hoxb-6 $6^{-}$mice frequently show first and second rib defects (Figs. $4 \mathrm{C}$ and $5 \mathrm{~B}, \mathrm{C}$; Table 1). The absence or shortening of a first rib in 

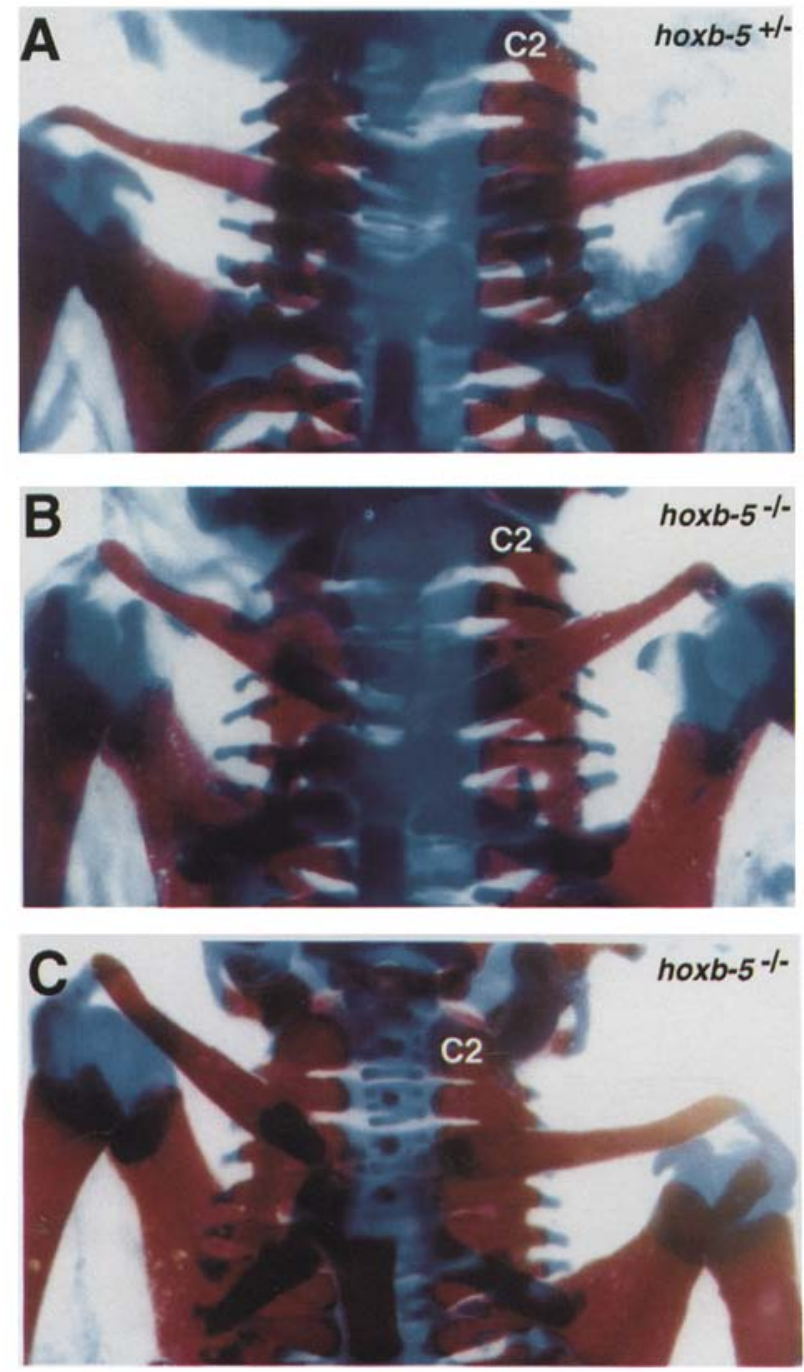

Figure 2. Forelimbs shifted rostrally in hox $b-5^{-}$mutant newborns. $(A, B, C)$ Ventral views of the lower cervical and upper thoracic regions of a hox $b-5^{-}$newborn heterozygote $(A)$ and two homozygous mutants $(B, C)$. The second cervical vertebra $(C 2)$ is indicated. $(B)$ A bilateral shift of the forelimbs in this animal results in a V-shaped shoulder girdle. (C) A unilateral shift of the left forelimb occurs in this animal.

these animals (Figs. $4 \mathrm{C}$ and $5 \mathrm{~B}, \mathrm{E}$ ) is coincident with a bifurcation of the second rib such that its upper branch articulates with the top of the sternum. This is unlike the wild-type (Fig. 4A) and heterozygote (not shown) pattern in which the first rib normally articulates with the top of the sternum. It should be noted that when present, this bifurcation occurs consistently at a point that demarcates bone and cartilage in the newborn animal.

The penetrance of this rib phenotype was not complete, occurring in only $50 \%$ of the hox $b-6^{-}$homozygotes examined. Frequently, true rib defects were restricted to one side, although they were often accompanied by the absence of rib heads on the opposite side of the T1 vertebra (see Fig. 8E, below; Table 1). Although a
T2 bifurcation was the predominant rib phenotype seen in hox $b-6^{-}$homozygotes, we have observed two variations on the expressivity of this trait. In many cases, it appears that a shortened dorsal first rib successfully articulates with the second rib bifurcation to form an $\mathrm{X}$ shape (Fig. 4D; Table 1). In another variation, which we interpret to be more severe, animals either have only a ventral first rib that is attached to the sternum or a gap between the most ventral and dorsal parts of the rib (Fig. 5C; Table 1).

Ribs are formed as ventrolateral projections that emanate from sclerotomes adjacent to the condensing thoracic vertebra and articulate with an independently formed sternum (Chen 1952, 1953). The appearance of both ventral Tl ribs and ventral rib bifurcations in hoxb$6^{-}$homozygotes prompted us to investigate rib development in hoxb- $6^{-}$mutants to determine when the bifurcations occurred. E13.5 embryos were stained for nerve and cartilage at a time prior to the appearance of the sternum. At this stage, embryos with a foreshortened first rib and a bifurcated second rib were clearly seen (Fig. 5B), as were embryos possessing a first rib gap (Fig. 5C).

To examine rib development at earlier stages, E11.5, E12.5, E13.5, and E14.5 embryos were stained in whole mount with the prechondrogenic cell marker peanut agglutinin (Götz et al. 1991). Prechondrogenic rib growth was first detectable in early E11.5 embryos and continued until E13.5 when prechondrogenic sternal rudiments begin to develop in a rostral-caudal direction. A T2 bifurcation was observed in embryos as early as E11.5 (Fig. $5 \mathrm{E})$. The dorsal and ventral aspects of the rib are clearly demarcated at this stage (Fig. 5D,E). Elements proximal to the spinal column are stained only lightly, whereas more lateral elements including the bifurcation are stained more heavily.

Nerve staining in this region also identified alterations in development of the first intercostal nerve in hoxb- $6^{-}$ mutant embryos. Normally this nerve enters in the region between the developing ribs (Fig. 5A). In animals where a bifurcation has occurred, the nerve appears to mimic the bifurcation by crossing medially over to the second intercostal nerve (Fig. 5B). This behavior of the first intercostal nerve is also observed in mutants possessing an X-shaped first and second rib (not shown). Alternatively, in animals where a rib gap has occurred, the nerve does not enter between the first and second rib but, instead, appears to lose its path (Fig. 5C).

\section{Overlapping cervicothoracic transformations in} hoxb- $6^{-}$and hox $-5^{-}$mutant mice

In addition to the shoulder and rib phenotypes that occur in hoxb-5- and hoxb-6 $6^{-}$homozygotes, respectively, a number of overlapping axial transformations are seen in homozygotes from both pedigrees (Figs. 4, 6 and 7; Table 1). Often the tuberculum anterior on the sixth cervical vertebra (C6) either has shifted position to $\mathrm{C} 7$ (Figs. 6B,D and $7 \mathrm{~B}, \mathrm{E})$ or is duplicated on the seventh cervical vertebra (Figs. 4B,C and Fig. 7C). In mutants, a new tuberculum anterior on $\mathrm{C} 7$ was accompanied by the appearance 
Figure 3. Forelimbs shifted rostrally in hox $b-5^{-}$mutant embryos. $(A, B)$ Ventral views of the lower cervical and upper thoracic regions of an E13.5 hoxb-5 $5^{-}$heterozygote $(A)$ and homozygous mutant $(B)$ immunostained with anti-neurofilament antibody to reveal neurons and counterstained with alcian blue to reveal cartilage. The fifth cervical vertebra $(C 5)$ is indicated. $(B)$ In the mutant, the scapula is shifted anteriorly relative to the cervical skeleton. The anterior end of the scapula sits above the fifth cervical vertebra and the fourth cervical nerve (white arrowhead), and the posterior end of the scapula (star) is now at the level of the second rib. In the homozygous mutant, the brachial plexus enters the forelimb more posteriorly (white arrow) by crossing the posterior end of the scapula instead of the middle, as seen in the heterozygote. The black arrow indicates that the rib head is also missing on this side of the animal. $(C, D)$ Nerve tracing of the bra-
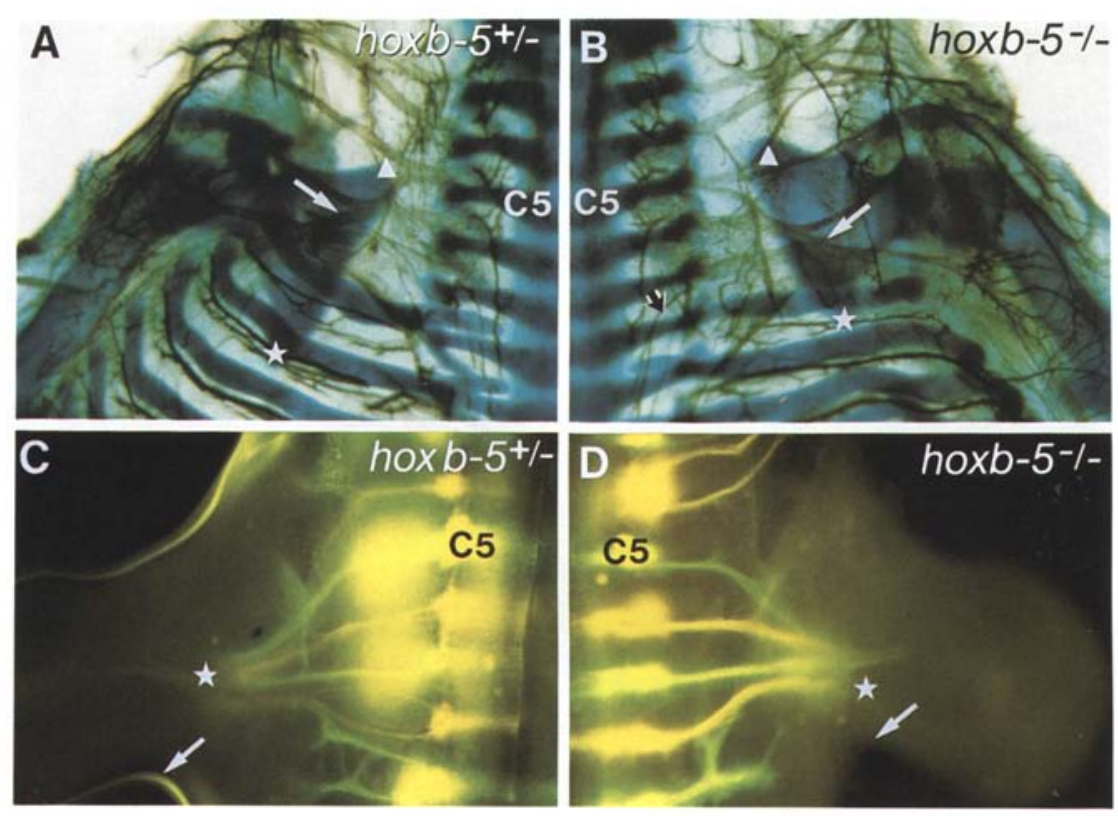
chial plexus in an E12.5 hoxb-5- heterozygote $(C)$ and homozygote $(D)$. Cervical ganglia of the plexus were injected alternately with the carbocyanine dyes $\mathrm{DiI}$ and $\mathrm{DiO}$. The fifth cervical nerve $(\mathrm{C} 5)$ is indicated. The relative trajectories of both plexuses are similar. However, the plexus (star) is closer to the posterior edge of the forelimb (arrow) in the mutant $(D)$ than in the control $(C)$, indicating that the forelimb bud is displaced rostrally in the mutant.

of a transverse foramina (Figs. 6B,D and 7B,C,E). Furthermore, histological analysis of homozygous mutants confirms that when the tuberculum anterior is present on C7, the vertebral artery is rerouted through the ectopic foramen to enter the cervical spinal column at $\mathrm{C} 7$ (Fig. $7 \mathrm{~B}, \mathrm{C}, \mathrm{E})$.

A duplication of the tuberculum anterior on $\mathrm{C} 7$ was interpreted as being a $\mathrm{C7} \rightarrow \mathrm{C} 6$ anteriorizing transformation, whereas a shift of this structure from $\mathrm{C} 6$ to $\mathrm{C} 7$ indicated that two anteriorizing transformations had occurred: $\mathrm{C} 6 \rightarrow \mathrm{C} 5$ and $\mathrm{C} 7 \rightarrow \mathrm{C} 6$. Similarly, the absence of this structure was considered to occur via a C6 $\rightarrow \mathrm{C} 5$ anteriorizing transformation. A third anteriorizing transformation was revealed by the absence of rib heads, the caput costae, on the first thoracic vertebra (T1) (Figs. 3B, $5 \mathrm{~B}, \mathrm{C}, 6 \mathrm{C}, \mathrm{D}$, and $7 \mathrm{D}, \mathrm{E})$. Analysis of $\mathrm{T} 1$ vertebrae from adult skeleton preparations demonstrated that those vertebrae that lacked rib heads had altered lateral processes, making them indistinguishable from C7 (Fig. 8D). These vertebrae were interpreted as having undergone a partial $\mathrm{T} 1 \rightarrow \mathrm{C} 7$ transformation. Although the absence of rib heads always accompanied a $\mathrm{Tl} \rightarrow \mathrm{C} 7$ transformation, the reverse was not found to be true: In adult homozygotes, some $\mathrm{Tl}$ vertebrae had normal rib head structures with altered lateral processes resembling those of $\mathrm{C7}$ (Fig. 8C).

Variability in the expressivity of these cervicothoracic phenotypes is seen in homozygotes from both pedigrees (Table 1). Frequently, defects are restricted to or are more severe on one side of the animal than on the other (Fig. 6D). Sometimes only a subset of these transformations will appear (Fig. 6B,C). Although for both pedigrees, the
$\mathrm{T} 1 \rightarrow \mathrm{C} 7$ transformation is most predominant, the frequency with which the $\mathrm{C} 6 \rightarrow \mathrm{C} 5$ and/or $\mathrm{C} 7 \rightarrow \mathrm{C} 6$ transformations either coappear with $\mathrm{Tl} \rightarrow \mathrm{C} 7$ or appear alone is greater in hoxb $-5^{-}$homozygotes. In hoxb- $6^{-}$ homozygotes the $\mathrm{C} 6 \rightarrow \mathrm{C} 5$ and/or $\mathrm{C} 7 \rightarrow \mathrm{C} 6$ transformations only occurred in combination with $\mathrm{T} 1 \rightarrow \mathrm{C} 7$. In addition, unlike the case of hoxb- $6^{-}$homozygotes in which the $\mathrm{T} 1 \rightarrow \mathrm{C} 7$ transformation often coappeared with defects of the rib, no true rib defects were observed in the hox $b-5^{-}$pedigree.

A progression in the stages of the $\mathrm{Tl} \rightarrow \mathrm{C} 7$ transformation appears to occur in the hox $b-5^{-}$and hoxb $-6^{-}$ animals (Fig. 8). In the first stage, which is frequently observed in hoxb $-5^{-}$homozygotes and to a lesser degree in hox $b-6^{-}$homozygotes, the T1 lateral processes resemble those of $\mathrm{C} 7$, although both ribs and rib heads remain associated with the $\mathrm{T} 1$ vertebra (Fig. $8 \mathrm{C}$ ). In the second stage, which occurs to the same extent in homozygotes from both pedigrees, one or both rib heads are missing from a Tl vertebra that resembles $\mathrm{C} 7$ (Fig. 8D). Finally, as is seen in only the hoxb $\cdot 6^{-}$homozygotes, the rib itself will be missing, resulting in a complete $\mathrm{T} 1 \rightarrow \mathrm{C} 7$ transformation (Fig. 8E). Thus far, we have only observed $\mathrm{T} 1$ vertebrae where one rib is missing, although frequently the opposite rib head will be absent (Fig. 8E; Table 1).

We find that the lateral processes of $\mathrm{C} 7$ and $\mathrm{Tl}$ are only distinguishable in preparations of adult vertebrae. As a result, it is likely that the number of partial $\mathrm{T} 1 \rightarrow \mathrm{C} 7$ transformations scored from newborn skeletal preparations is greater than that represented in Table 1. In adult skeletal preparations of both hoxb-5 $5^{-}$and 


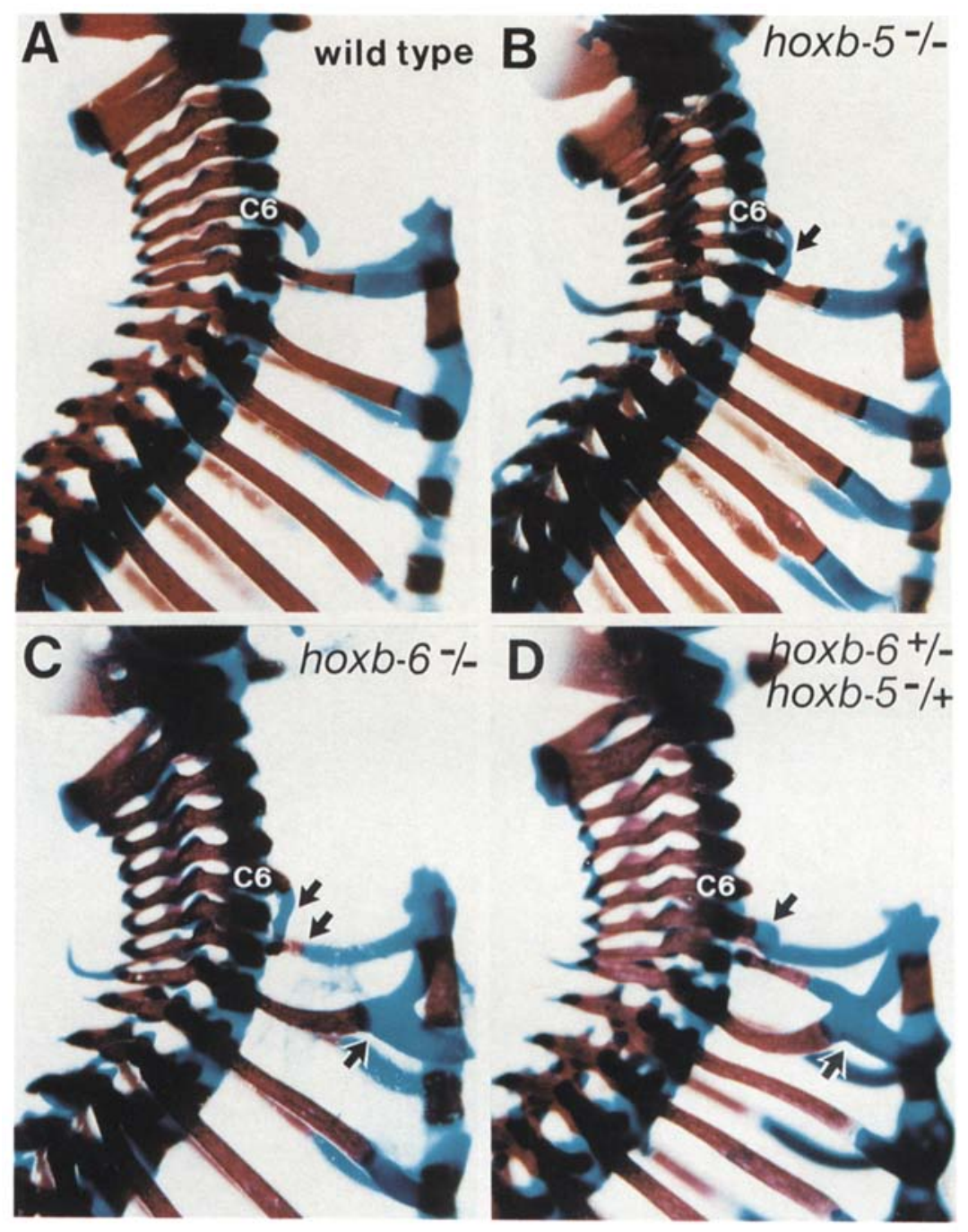

Figure 4. Alterations of the cervicothoracic skeleton in hox $b-5^{-}$and hox $b-6^{-}$mutants and transheterozygotes. Lateral views of newborn skeleton preparations of wild type $(A)$, hoxb$5^{-}$homozygote $(B)$, hoxb-6- homozygote $(C)$, and hoxb-5 $5^{-} / h o \times b-6^{-}$transheterozygote $(D)$ are represented. The sixth cervical vertebra $(C 6)$ is indicated. $(B)$ The arrow points to the fused, duplicated tuberculum anterior present on the seventh cervical vertebra. $(C)$ The top arrow points to a tuberculum anterior that is altered in this animal. In addition, the first rib is absent on the right side (middle arrow) and a bifid second rib occurs (bottom arrow). (D) The tuberculum anterior shifts from $\mathrm{C} 6$ to $\mathrm{C} 7$ on both sides of this animal (top arrow). The first and second ribs are also bifid (bottom arrow) and come together to form an $\mathrm{X}$ on the right side of this animal. hox $b-6^{-}$homozygotes, $(18$, and 8 , respectively $)$, all animals display alterations of their $\mathrm{T} 1$ lateral processes, even when no other cervicothoracic phenotypes are apparent. Therefore, it is likely that the penetrance of cervicothoracic phenotypes is higher than indicated in $\mathrm{Ta}$ ble 1 .

\section{Cervicothoracic phenotypes in hoxb- $5^{-} /$hoxb- $6^{-}$ transheterozygotes}

Because of the considerable overlap in cervicothoracic phenotypes observed in both the hoxb-5 $5^{-}$and hoxb-6 pedigrees, we considered the hypothesis that hox $b-5$ and hox $b-6$ may act in concert to specify the development of the lower cervical-upper thoracic region of the animal. Despite the fact that both the hoxb $-5^{-}$and hoxb $-6^{-} \mathrm{mu}-$ tations gave rise to truly recessive phenotypes, interactions between hoxb-5 and hoxb-6 might be revealed in transheterozygotes (i.e., hoxb $-5^{-}$, hoxb $-6^{+} /$hoxb $-5^{+}$ hox $b-6^{-}$micel.

In the initial experiments, hoxb $-5^{-}$and hox $b-6^{-}$homo- zygotes were crossed to generate two litters of transheterozygotes. Of 11 newborn progeny, 8 animals showed cervicothoracic phenotypes typical of homozygotes from either pedigree. One animal possessed bilateral transformations of $\mathrm{C} 6, \mathrm{C} 7$, and $\mathrm{T} 1$ as well as an $\mathrm{X}$-shaped first and second rib (Fig. 4D).

To confirm these results, as well as to generate heterozygous control littermates in the same litter, hoxb$6^{-1-} \times h o x b-5^{+1-}$ and hoxb $-5^{-1-} \times$ hoxb $-6^{+1-}$ crosses were initiated. Both crosses gave rise to litters where approximately half of the offspring were transheterozygotes and half were control heterozygotes.

Both types of crosses resulted in transheterozygotes bearing cervicothoracic phenotypes (Table 1), whereas no phenotypes were observed in control animals heterozygous for one or the other mutation (not shown). Of sixteen transheterozygotes derived from the first cross, 12 showed cervicothoracic phenotypes, including one with a rib bifurcation. Similarly, the second cross produced 10 of 13 transheterozygotes with cervicothoracic phenotypes. As was seen for both the hoxb-5- and hoxb- 

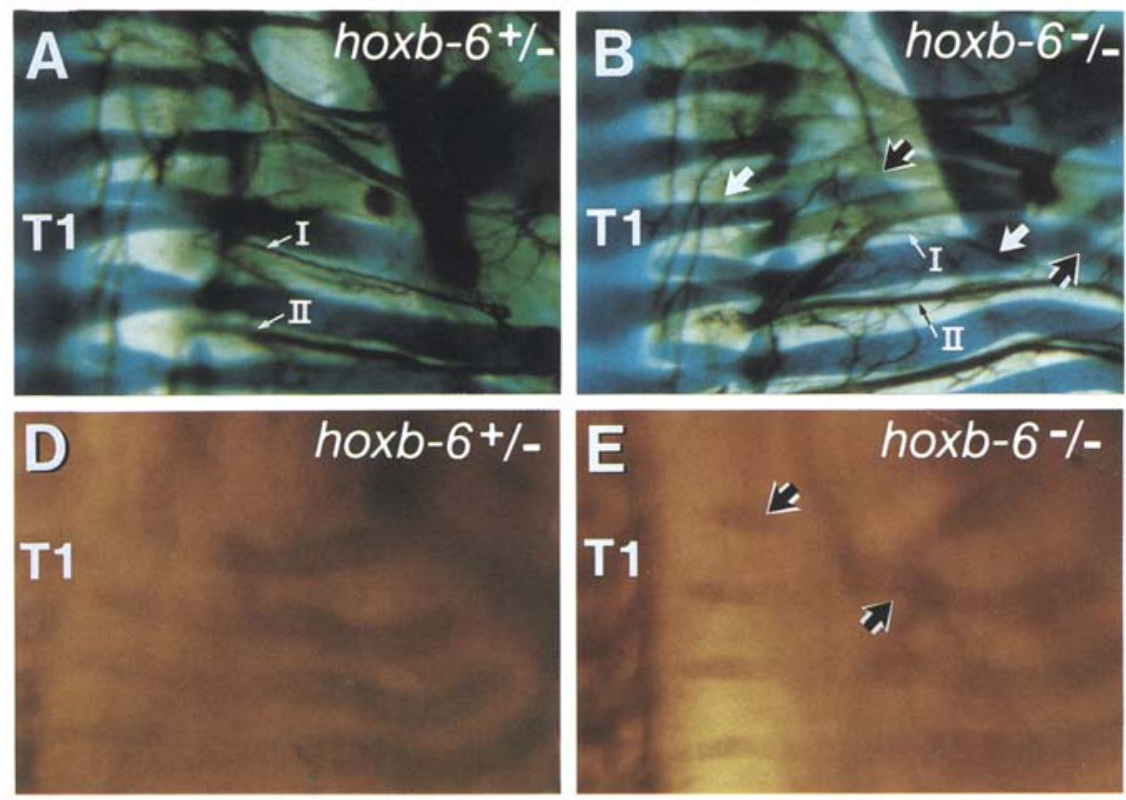

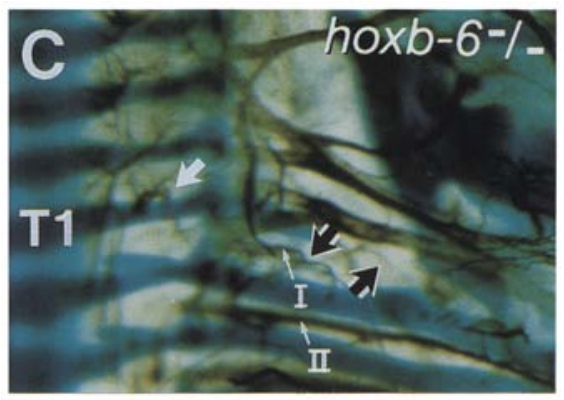

Figure 5. Altered first and second ribs in hox $b-6^{-}$mutant embryos. $(A, B, C)$ Ventral views of the lower cervical, upper thoracic region of E13.5 embryos immunostained with anti-neurofilament antibody to reveal neurons and counterstained with alcian blue to reveal cartilage: $(A)$ hoxb- $6^{-}$heterozygote; $(B, C)$ homozygotes. The first thoracic vertebra $(T 1)$ is indicated, as are the first (I) and second (II) intercostal nerves. (B) In this mutant, the $\mathrm{T} 1$ rib head is missing (left white arrow), the first rib is shortened (left black arrow), the second rib is bifurcated (right black arrow), and the trajectory of the first intercostal nerve is altered such that it crosses over to the second intercostal nerve (right white arrow). $(\mathrm{C})$ In this mutant the T1 rib head is absent (left white arrow), a gap appears in the $\mathrm{Tl}$ rib (right black arrow) and the first intercostal nerve does not develop (left black arrow). (D,E) Ventral views of the lower cervical, upper thoracic regions of E11.5 embryos stained with HRP-conjugated peanut agglutinin (PAG). Rib bifurcation is observed in precartilagenous rib blastema: $(D)$ hox $b-6^{-}$heterozygote; $(E)$ homozygote. $(D)$ Dorsal and ventral aspects of the rib can be distinguished by the difference in the intensity of PAG staining. Ventral portions of the rib stain more intensely at this stage. $(E)$ Bifurcation of the second rib is observed in early rib blastema at the border between the dorsal and ventral aspects of the rib (bottom arrow). A shortened first rib also occurs in this embryo (top arrow).

$6^{-}$homozygotes, the penetrance and expressivity of these traits were variable. However, the variability of this phenotype in transheterozygotes appears to be similar to that observed in hoxb-5 $5^{-}$and hoxb-6 $6^{-}$homozygotes. For instance, the frequency of $\mathrm{C} 6 \rightarrow \mathrm{C} 5$ and/or $\mathrm{C} 7 \rightarrow$ C6 transformations in transheterozygotes is $52 \%$, whereas in hoxb $-5^{-}$and in hoxb- $6^{-}$homozygotes, it is 57 and $36 \%$ respectively. In the hox $b-6^{-}$homozygotes these transformations only occur in conjunction with a $\mathrm{Tl} \rightarrow \mathrm{C} 7$ transformation, whereas for both hox $b-5^{-}$homozygotes and transheterozygotes these transformations can appear on their own.

hoxb- 6 and hoxb- 5 expression is unaltered in hoxb-5 $5^{-}$and hoxb- $6^{-}$mutants, respectively

Because the hoxb-5 and hoxb-6 mutant chromosomes failed to complement each other with respect to the cervicothoracic phenotype, it was important to determine whether hoxb-5 or hoxb-6 gene expression was perturbed. Alteration in the expression of one gene in the mutant background of the other could explain why overlapping cervicothoracic phenotypes arise in the two mutants. In wild-type E12.5 embryos, both hoxb-6 and hoxb-5 are expressed in the spinal cord to the level of the posterior myelencephalon. In the vertebral column, hox $b-6$ has been reported to be expressed to the level of prevertebra $(\mathrm{pv})$ 8, while the expression of hoxb-5 extends to pv2 (Graham et al. 1989; Gunt et al. 1990).
The expression patterns of hoxb- 6 and hoxb-5 in hoxb$5^{-}$and hoxb-6 $6^{-}$homozygotes, respectively, did not differ from the wild-type patterns (Fig. 9). Using a hoxb-6 specific RNA probe, we found that expression of hoxb-6 within the vertebral column extended rostrally to the level of pv8 in both wild-type and hoxb-5- homozygous embryos (Fig. 9A-D). hoxb-5 expression was monitored both with a specific RNA probe and with an antibody directed against hoxb-5 protein (Wall et al. 1992). Wildtype and hox $b-6^{-}$mutant embryos immunostained for hoxb-5 protein were counterstained with alcian blue to localize expression to the prevertebrae. No differences in the expression pattern of hoxb-5 protein or RNA were apparent in wild-type and hoxb-6 $6^{-}$homozygous embryos. Rostrally, both RNA and protein extended to pv2. However, although hoxb-5 protein expression was found to extend caudally to only pv8 in both wild-type and hoxb-6 $6^{-}$homozygotes (Fig. 9E,F), RNA expression was observed to extend caudally far beyond that point (Fig. 9G,H; Holland and Hogan 1988; Gaunt et al. 1990), implying that hoxb-5 is regulated post-transcriptionally.

\section{Discussion}

We have used targeted gene disruption to assess the roles of hoxb-5 and hoxb-6 during murine development. A neo-poly|A $/$ cassette was inserted into first exon coding sequences of hoxb-5 and hoxb-6, respectively. This insertion not only disrupts the reading frame of the target 
Table 1. Cervicothoracic phenotypes in newborn hoxb-5 ${ }^{-}$, hoxb-6 $6^{-}$homozygotes and transheterozygotes

\begin{tabular}{|c|c|c|c|c|c|c|c|c|c|c|c|c|c|c|}
\hline \multirow{2}{*}{$\frac{\text { Genotype }}{h o x b-6^{-1-}}$} & \multirow[t]{2}{*}{$\mathrm{C} 6 \rightarrow \mathrm{C} 5$} & $\mathrm{C} 7 \rightarrow \mathrm{C} 6$ & \multicolumn{2}{|c|}{$\mathrm{Tl} \rightarrow \mathrm{C} 7$} & \multirow{2}{*}{$\begin{array}{l}\text { Ribs } \\
1^{\mathrm{a}} \\
1^{\mathrm{e}} \\
1^{\mathrm{a}, \mathrm{d}} \\
1^{\mathrm{b}, \mathrm{d}}\end{array}$} & \multicolumn{2}{|c|}{$\begin{array}{l}\mathrm{C} 6 \rightarrow \mathrm{C} 5 \\
\mathrm{C} 7 \rightarrow \mathrm{C} 6\end{array}$} & \multirow[t]{2}{*}{$\begin{array}{l}\mathrm{C} 6 \rightarrow \mathrm{C} 5 \\
\mathrm{~T} 1 \rightarrow \mathrm{C} 7\end{array}$} & \multirow{2}{*}{$\begin{array}{l}\text { C6 } \rightarrow \text { C5 } \\
\text { ribs } \\
1^{a} \\
1^{a, d} \\
\\
\quad 1^{a, c, d}\end{array}$} & $\begin{array}{c}\mathrm{C} 7 \rightarrow \mathrm{C} 6 \\
\mathrm{~T} 1 \rightarrow \mathrm{C} 7 \\
1^{\mathrm{g}}\end{array}$ & $\frac{\begin{array}{l}\mathrm{C} 7 \\
\text { ribs }\end{array}}{1^{\mathrm{a}}}$ & \multicolumn{2}{|c|}{$\begin{array}{l}\mathrm{C} 6 \rightarrow \mathrm{C} 5 \\
\mathrm{C} 7 \rightarrow \mathrm{C} 6 \\
\mathrm{~T} 1 \rightarrow \mathrm{C} 7\end{array}$} & \multirow{2}{*}{$\begin{array}{l}\mathrm{C} 6 \rightarrow \mathrm{C} 5 \\
\mathrm{C} 7 \rightarrow \mathrm{C} 6 \\
\text { ribs } \\
2^{\mathrm{c}, \mathrm{d}} \\
1^{\mathrm{c}, \mathrm{f}}\end{array}$} \\
\hline & & & 3 & 5 & & & & & & $1^{\mathrm{g}}$ & $1^{\mathrm{a}}$ & $\begin{array}{l}1 \\
1^{\mathrm{d}}\end{array}$ & & \\
\hline$h o x b-5^{-1-}$ & 1 & 2 & 8 & 1 & & 1 & 2 & & & $\begin{array}{l}3 \\
2^{\mathrm{g}} \\
1^{\mathrm{d}}\end{array}$ & & $\begin{array}{l}4 \\
2^{\mathrm{d}}\end{array}$ & $\begin{array}{l}1^{\mathrm{h}} \\
1^{\mathrm{i}}\end{array}$ & \\
\hline $\begin{array}{l}h o \times b-5^{-1+} \\
h o x b-6^{+1-}\end{array}$ & & 1 & 7 & 2 & & 1 & $\begin{array}{l}1^{\mathrm{h}} \\
1\end{array}$ & 1 & & 3 & & $\begin{array}{l}3^{\mathrm{d}} \\
2 \\
1^{\mathrm{k}}\end{array}$ & $\begin{array}{l}2 \\
2^{\mathrm{i}}\end{array}$ & $\begin{array}{l}1^{a, d} \\
1^{a, j} \\
1^{c, j}\end{array}$ \\
\hline
\end{tabular}

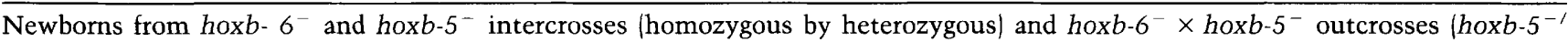
- $\times$ hox $b-6^{-1-}$, hox $b-6^{-1-} \times$ hoxb $-5^{+1-}$, hox $b-5^{-1-} \times$ hox $\left.b-6^{+1-}\right)$ were analyzed for skeletal defects. Heterozygotes derived from

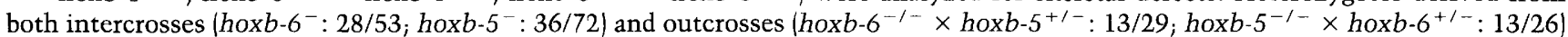
showed no skeletal defects. The array of cervicothoracic phenotypes observed in homozygotes and transheterozygotes is listed. A $\mathrm{C} 6 \rightarrow \mathrm{C} 5$ transformation results in the loss of a tuberculum anterior from the sixth cervical vertebra. In a C7 $\rightarrow$ C6 transformation, a tuberculum anterior and a vertebral foramen appear on the seventh cervical vertebra. A Tl $\rightarrow \mathrm{C} 7$ transformation is manifest by the absence of a rib head on the first thoracic vertebra. Ribs refer to changes in the structure of the first and/or second rib. The T1 rib head is invariably absent from the side(s) showing a rib defect. Animals that displayed unilateral or bilateral phenotypes are listed on the left or right side of each category column, respectively. $3 / 25$ hox $b-6^{-}$homozygotes, $6 / 35$ hoxb-5 homozygotes, and $10 / 40$ transheterozygotes showed no phenotype. The phenotypes observed in transheterozygotes do not appear to be influenced by the sex of the mice donating the hox $b-5^{-}$or hox $b-6^{-}$mutant alleles; therefore, imprinting of this locus does not appear to be a factor in controlling the activities of these genes.

${ }^{\mathrm{a}} \mathrm{T} 1 \mathrm{rib}$ shortened or missing and $\mathrm{T} 2$ bifurcation.

bVentral T1 rib only.

${ }^{\mathrm{C}} \mathrm{T} 1$ and $\mathrm{T} 2$ ribs form an $\mathrm{X}$

d $\mathrm{T} 1 \rightarrow \mathrm{C} 7$ is bilateral.

${ }^{\mathrm{e}} \mathrm{Gap}$ between dorsal and ventral $\mathrm{T} 1 \mathrm{rib}$.

fBilateral rib defect.

sUnilateral transformations occur on opposite sides.

${ }^{\mathrm{h}} \mathrm{C} 6 \rightarrow \mathrm{C} 5$ is unilateral.

${ }^{\mathrm{i}} \mathrm{T} 1 \rightarrow \mathrm{C} 7$ is unilateral.

Unilateral rib defects occur.

${ }^{\mathrm{k}} \mathrm{C} 7 \rightarrow \mathrm{C} 6$ is bilateral.

gene but also results in premature termination of the native transcript due to the presence of an effective poly(A) addition signal (Condie and Capecchi 1993; Mansour et al. 1993; Kostic and Capecchi 1994).

In situ expression studies have localized hoxb-5 mRNA and protein to both neuroectodermal and mesodermal lineages in the developing mouse embryo (Holland and Hogan 1988; Kuritani and Wall 1992; Wall et al. 1992). Migrating neural crest cells, which express hoxb-5, are thought to contribute to the formation of the nodose ganglion as well as to epibranchial derivatives of the fourth and sixth pharyngeal arches. Histological analysis of hox $b-5^{-}$homozygotes reveals no defects in the structure of the vagus nerve or any other structures in the circumpharyngeal area. As well, there are no defects in the lungs, gastrointestinal tract or kidneys, all of which express hoxb-5 during organogenesis. Similarly, no defects are observed in the ventrolateral region of hoxb-6 $6^{-}$mutant mice, including kidneys, forelimbs and hindlimbs, all of which express hoxb-6 (Shen et al. 1991; Shughart et al. 1991; Eid et al. 1993). The absence of mutant phenotypes in these tissues, particularly during organogenesis, might derive from functional redundancies among Hox genes. Multiple Hox genes are expressed in the anlage of tissues giving rise to the lungs, heart, kidneys, gastrointestinal tract, and reproductive organs. The role of Hox genes in the formation of these organs may become evident only in mice containing multiple Hox gene mutations.

Instead, defects in hox $b-5^{-}$and hoxb-6- mutant mice are restricted to three classes. Two of the classes, defects in the position of the forelimbs and defects in the formation of the first two ribs, are unique to homozygous mutants of hoxb-5 $5^{-}$and hoxb-6 ${ }^{-}$, respectively. The third class, which appears in both homozygous mutants, is an anteriorizing homeotic transformation of cervicothoracic vertebrae $\mathrm{C} 6$ through $\mathrm{T} 1$.

Surprisingly, although the $\mathrm{C} 6 \rightarrow \mathrm{T} 1$ homeotic transformations are never observed in mice heterozygous for either the hoxb $-5^{-}$or hoxb $-6^{-}$mutation, they do appear in hoxb-5, hoxb-6 transheterozygotes. Thus, by this genetic complementation criterion, these two individual mutations in separate genes behave as alleles of the same gene. This phenomenon of nonallelic noncomplementation has been described in yeast, Caenorhabditis elegans, and Drosophila (Rine and Herskowitz 1987; Stearns and Botstein 1988; Hays et al. 1989; Heitman et al. 1991; Varkey et al. 1993 and references therein) and 
Figure 6. Variable expressivity of cervicothoracic transformations in hoxb-5 $5^{-}$ and hox $b-6^{-}$homozygous newborns. Panels represent rostral views of cervical and thoracic vertebrae in one wild-type $(A)$, two hoxb-5- $(B, C)$, and one hoxb- $6^{-}$homozygote $(D)$. Ribs were cut free of the sternum. (A) The fourth cervical (C4) through to the second thoracic (T2) vertebrae are indicated, as are a tuberculum anterior (TA), vertebral foramen (VF), and rib head (or caput costae, CC). $(B)$ Two of three cervicothoracic transformations occur. The tuberculae anterior are absent from $\mathrm{C} 6$ and shifted to $\mathrm{C7}$, also resulting in new vertebral foramina on $\mathrm{C} 7$ (indicated by arrows). (C) The third vertebral transformation represented in this animal shows the absence of rib heads (arrows), resulting in a $\mathrm{Tl}$ vertebra that resembles C7 vertebrae with cervical ribs. $(D)$ All three cervicothoracic transformations occur on one side of this animal (indicated by arrows).
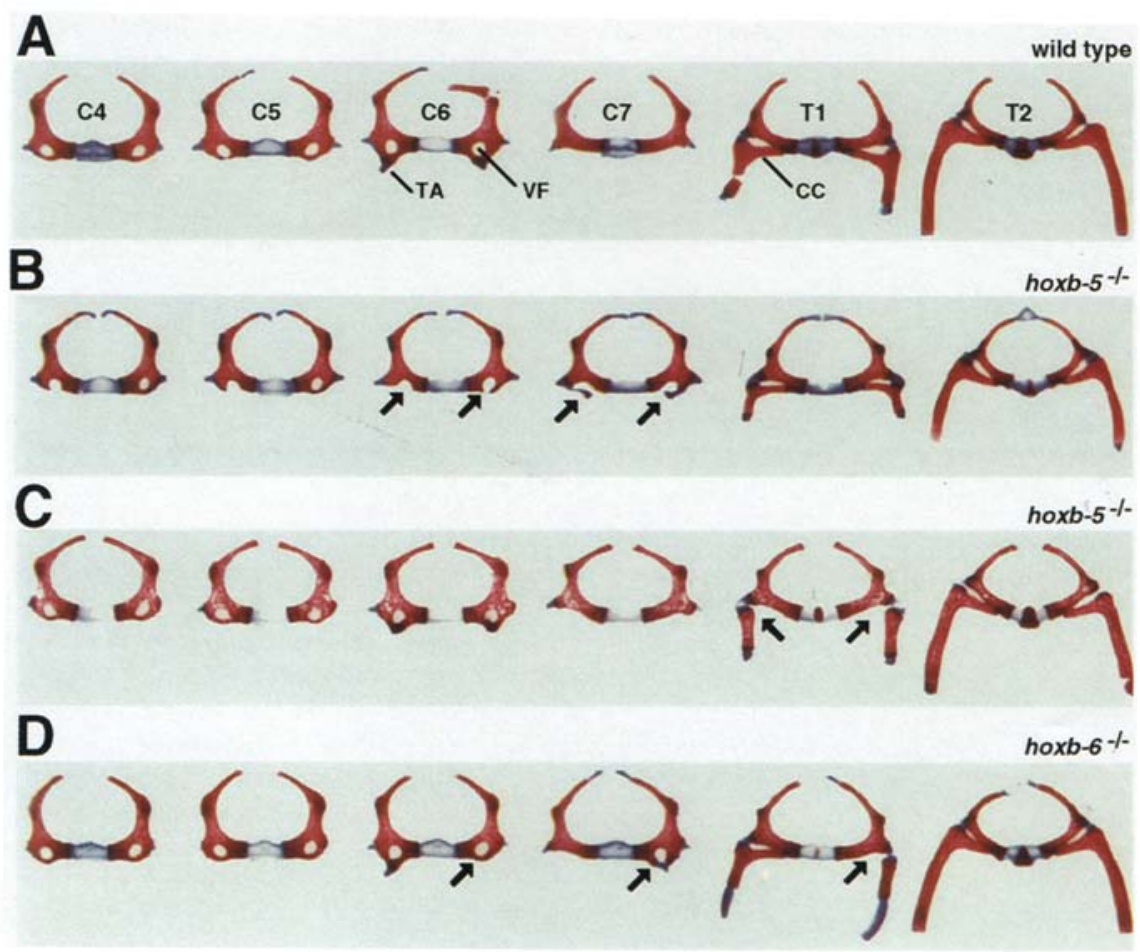

has often been found to involve disruption of a functional complex formed between the affected gene products.

A model to explain how the hoxb-5 and hoxb-6 mutations result both in unique phenotypic consequences and in a common phenotype that displays nonallelic noncomplementation is that these gene products function as homodimers and as heterodimers with the common phenotype, for example, being mediated by the heterodimer. In mice heterozygous for either the hox $b-5^{-}$or hox $b-6^{-}$ mutation, the concentration of the homodimer and of the heterodimer would be one-half of that present in the wild type. Because such mice show no apparent phenotype, this level of gene product is presumed to be sufficient for normal development. However, in transheterozygotes, the amount of heterodimer would be reduced to one-fourth the normal level. This level of gene product is postulated to be below the threshold required for normal development of the cervicothoracic region. Consistent with such a model, studies involving transfection of cultured mammalian cells, as well as biochemical studies, suggest that protein-protein complexes can form between separate Hox gene products (Zappavigna et al. 1994).

However, we favor interpreting the nonallelic noncomplementation observed in hox $b-5^{-}$, hox $b-6^{-}$transheterozygotes in terms of the amount of gene product required to mediate a function. For the phenotype held in common, hoxb-5 and hoxb-6 would be postulated to perform near identical roles. In normal animals the amount of gene product for this function would then be $4 \times$. In mice heterozygous for either the hox $b-5^{-}$or hox $b-6^{-}$ mutation, the amount of gene product would be $3 \times$ and would be sufficient to permit proper development of these vertebrae. However, in transheterozygotes or in mice homozygous for either the hox $b-5^{-}$or the hox $b-6^{-}$ mutation, the level of gene product would be $2 \times$ and would not be sufficient for normal development of this region. Furthermore, the similar extent of variability in the penetrance and expressivity of this phenotype in hox $b-5^{-}$homozygotes, in hox $b-6^{-}$homozygotes, and in hox $b-5^{-}$, hoxb $-6^{-}$transheterozygotes could be explained by the presence of the $2 \times$ amount of gene product in these mice. Irrespective of the model, observing nonallelic noncomplementation between hoxb-5 $5^{-}$and hox $b-6^{-}$transheterozygotes indicates that these genes interact to properly specify the identity of the C6 to T1 vertebrae.

\section{The limb phenotype in hoxb-5 $5^{-}$mutant mice}

Frequently in hoxb-5 homozygotes the position of the shoulder girdle is shifted anteriorly by one or two cervical vertebrae. Because the clavicle bones of the shoulder apparatus are anchored to the top of the sternum, this defect results in a pronounced V-shaped shoulder girdle. The shifting of the limb bud is apparent as early as E12.5, prior to the elaboration of the mouse musculature. In vertebrates, the limb develops as a bud of mesenchymal cells originating from the adjacent lateral plate mesoderm (Chavellier et al. 1977). In mice, hoxb-5 is expressed in the anteroproximal region of the early forelimb bud (Wall et al. 1992). This expression may occur de novo in the limb bud or it may result from cells that have migrated from the adjacent mesoderm that expresses hox $b-5$ at an earlier stage. The above observations suggest that Hox genes not only govern the formation of the 

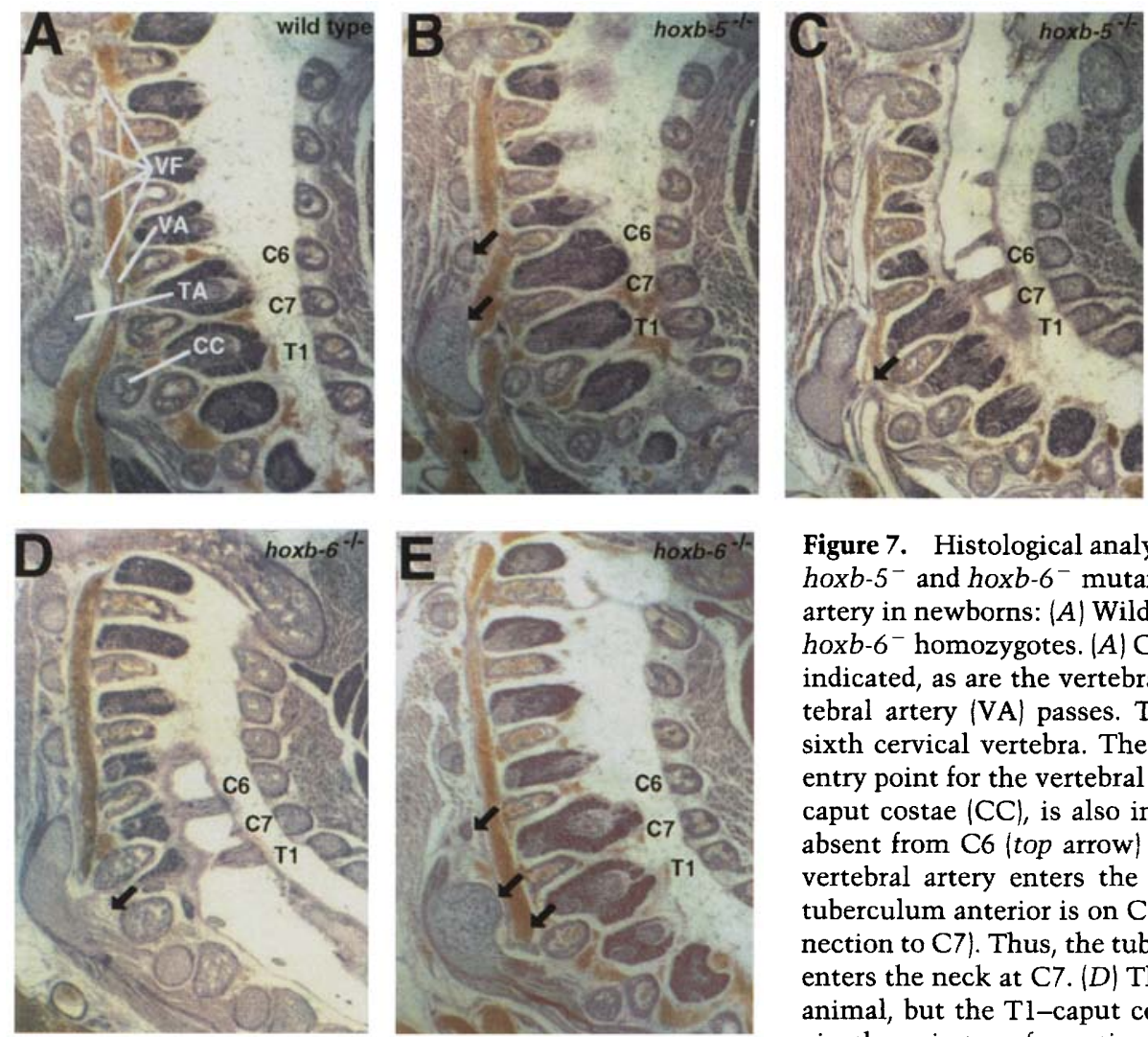

Figure 7. Histological analysis of cervicothoracic transformations in hox $b-5^{-}$and hox $b-6^{-}$mutants. Parasagittal sections of the vertebral artery in newborns: $(A)$ Wild type; $(B, C)$ hoxb-5- homozygotes; $(D, E)$ hox $b-6^{-}$homozygotes. (A) Cervicothoracic vertebrae $(\mathrm{C} 6, \mathrm{C} 7, \mathrm{~T} 1)$ are indicated, as are the vertebral foramina $(V F)$, through which the vertebral artery $(\mathrm{VA})$ passes. The tuberculum anterior $(\mathrm{TA})$ is on the sixth cervical vertebra. The vertebral foramen on $\mathrm{C} 6$ is the normal entry point for the vertebral artery into the neck. The $\mathrm{T} 1 \mathrm{rib}$ head, or caput costae $(C C)$, is also indicated. $(B)$ The tuberculum anterior is absent from $\mathrm{C} 6$ (top arrow) and appears on $\mathrm{C} 7$ (bottom arrow). The vertebral artery enters the cervical spinal column at $C 7 .(C)$ The tuberculum anterior is on $\mathrm{C} 7$ in addition to $\mathrm{C} 6$ (arrow indicates connection to C7). Thus, the tuberculae are fused and the vertebral artery enters the neck at C7. $(D)$ The tuberculum anterior is normal in this animal, but the T1-caput costae is absent (arrow). (E) All three cervicothoracic transformations occur in this animal. The tuberculum anterior is absent from $\mathrm{C} 6$ (top arrow) and is shifted to $\mathrm{C} 7$ (middle arrow), where the vertebral artery enters the neck. In addition, the T1-caput costae is absent (bottom arrow).

bones in the limb (Dolle et al. 1993; Small and Potter 1993; Davis and Capecchi 1994) but also the positioning of the limbs relative to the axial skeleton, perhaps by providing positional cues to the mesoderm that will give rise to the limb bud. It is curious that in hoxb-5 homozygotes, the shift in the position of the limb bud relative to the axial skeleton and the change in the identity of the cervicothoracic vertebra show opposite directionality. It is as if specification of the position of the forelimb is independent of the identity of the axial skeleton.

\section{The costal phenotype in hoxb- $6^{-}$mutant mice}

Many hox $b-6^{-}$mutants have alterations in the development of the first and second ribs. In cases where the dorsal portion of the first rib is absent or shortened, a ventral bifurcation of the second rib is observed, which articulates with the sternum at the level of the first rib. This phenotype is invariably unilateral and results in a thoracic hemivertebra bearing the likeness of the seventh cervical vertebra. The bifurcation of the second rib is evident as early as E11.5, suggesting that the dorsal and ventral aspects of the rib are specified early in costal development. Formation of ventral ribs may involve sensing the presence of the adjacent rostral rib because in its absence a new ventral branch is elaborated. In hoxb$6^{-}$mutants that display first and second rib defects, the development of the first intercostal nerve is also altered (Fig. 5B,C), suggesting that communication is an important component of costal development of both bone and nerve. Furthermore, it has been suggested that costal derivatives of the sclerotome and myotome also communicate because disruption of the myotome-specific gene myf-5 results in rib defects (Braun et al. 1992).

\section{Cervicothoracic homeotic transformations}

In hox b-5 and hoxb-6- homozygotes, we observe overlapping anteriorizing transformations of the cervicothoracic vertebrae $\mathrm{C} 6, \mathrm{C} 7$, and $\mathrm{Tl}$. In both mutants, the $\mathrm{C} 6 \rightarrow \mathrm{C} 5$ transformation is frequently accompanied by a $\mathrm{C} 7 \rightarrow \mathrm{C} 6$ transformation; together these are manifest by displacement of the tuberculum anterior from $\mathrm{C} 6$ to $\mathrm{C7}$. This shift also results in the appearance of a transverse foramen on $\mathrm{C} 7$ and entry of the vertebral artery into the neck at $\mathrm{C} 7$, rather than $\mathrm{C} 6$ (Figs. 6B,D and 7B,E). In newborns, the $\mathrm{Tl} \rightarrow \mathrm{C} 7$ transformation is manifest by the absence of rib heads (caput costae) from the first thoracic vertebra, such that $\mathrm{T} 1$ resembles a $\mathrm{C} 7$ vertebra with cervical ribs (Figs. 6C,D and 7D). In homozygous adults, we observe that the lateral processes of these $\mathrm{T} 1$ vertebrae are indistinguishable from those of $\mathrm{C} 7$ (Fig. 8). Because these $\mathrm{T} 1$ vertebrae have ribs associated with them, this transformation is not complete. 


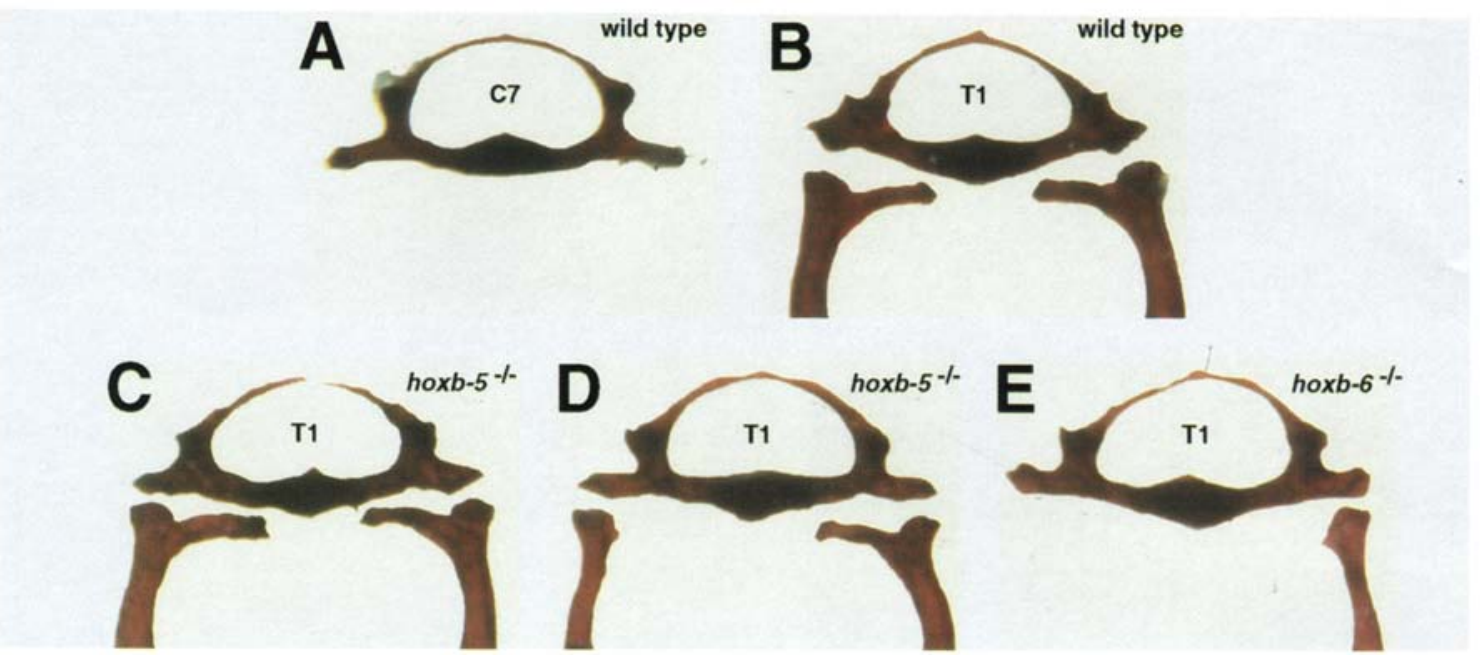

Figure 8. Linear progession of the $\mathrm{T} 1 \rightarrow \mathrm{C} 7$ transformation in hoxb-5 $5^{-}$and hoxb-6 $6^{-}$mutants. Shown are rostral views of alizarin red-stained, adult vertebrae following dissection: wild-type seventh cervical $(A, C 7)$ and first thoracic vertebrae $(B, T 1), T 1$ vertebrae from two hox $b-5^{-}$homozygotes $(C, D)$, and one hoxb $-6^{-}$homozygote $(E)$. Ribs were removed from $T 1$ vertebrae to reveal the lateral processes of each vertebra. In wild-type adult vertebrae, the lateral processes of $\mathrm{C} 7$ lie at right angles to the vertebral body and thus are distinguishable from those of $\mathrm{Tl}$, where this sharp right angle does not exist. Homozygous mutants of hox $b-5^{-}(D)$ or hox $b-6^{-}(E)$ that display rib defects invariably have Tl vertebrae with processes resembling those of $C 7$. In $D$, only the left rib head is missing and yet both lateral processes are similar to those of $C 7$. In $E$, a rib is missing from the left side representing a complete $\mathrm{T} 1 \rightarrow \mathrm{C} 7$ transformation on this side of the vertebra. $(C)$ Even in animals showing no overt defect, the processes of the T1 vertebra appear to be altered towards those of $\mathrm{C} 7$.

The development of the axial skeleton in vertebrates occurs via a complex set of processes involving cell migration, cell differentiation, and cell-cell interactions (Verbout 1985; Christ and Whiting 1992; Balling et al. 1993). It is likely that a number of Hox genes, in addition to hoxb-5 and hoxb-6, are involved in the specification of the lower cervical and upper thoracic region of the animal. Recently, the phenotypes of mice with disruptions in hoxa-5 and hoxa-6, genes that are paralogs of hoxb-5 and hoxb-6, respectively, have been reported (Jeannotte et al. 1993; Kostic and Capecchi 1994). Interestingly, both hoxa- $5^{-}$and hoxa- $6^{-}$homozygotes have ribs on C7. Therefore, mutations in hoxa-5/hoxa-6 and in hoxb-5/hoxb-6 have opposing consequences on the specification of the $\mathrm{C} 7 \rightarrow \mathrm{Tl}$ transition region, the former giving rise to $\mathrm{C} 7$ vertebrae that resemble $\mathrm{T} 1$ (a posterior transformation) and the latter giving rise to $\mathrm{T} 1$ vertebrae that are similar to $\mathrm{C} 7$ (an anterior transformation). The opposite polarities exhibited by these genes in specifying the same vertebrae suggest that this transcriptional complex may have a built-in ability to make adjustments during development and thereby be sensitive to feedback circuitry that would mediate these adjustments. We anticipate that opposite polarities in the function of Hox genes participating in the formation of common structures will be found to be a recurring, rather than an isolated, theme.

One clue that adjustments can be made during development is the common observation that the consequences of gene disruptions can be unilateral or show more severe defects on one side of the mutant animal than on the other. The sidedness of the mutant defects appears to be random. This property is not specific to mutations in hoxb-5 or hoxb-6 but is observed in most, if not all, mice with Hox mutations. Furthermore, it has been observed in mice with targeted mutations in genes unrelated to the Hox genes. A particularly striking example is observed in $f g f-3^{-}$homozygotes (Mansour et al. 1993). These mice show severe defects in the formation of the inner ear. However, $80 \%$ of the mutant mice have one completely defective inner ear and one apparently functional inner ear. This variability in the expressivity of the mutation cannot be attributed to "leakage" of the mutation because the documentation that it is a null mutation is strong. Furthermore, variation in the genetic background cannot account for this variability in expressivity because the variability is observed within individual mutant animals. Rather, we must postulate that there is a gene, or genes, that is compensating for the mutation and that the utilization of compensatory circuits is different on one side of the mutant animal relative to the other. Compensation for mutations could be a stochastic process, or reflect an adjustment to the effects of the mutations. If the latter is true, it is unlikely that compensations during development would occur solely in response to a mutation but, rather, would reflect a process occurring during normal development.

\section{Relation to human disorders}

Unilateral defects are a common feature of several human congenital disorders, and it is interesting that several of the defects that we observe in hoxb-5 $-5^{-}$and hoxb$6^{-}$mutants are also observed in various syndromes seen 

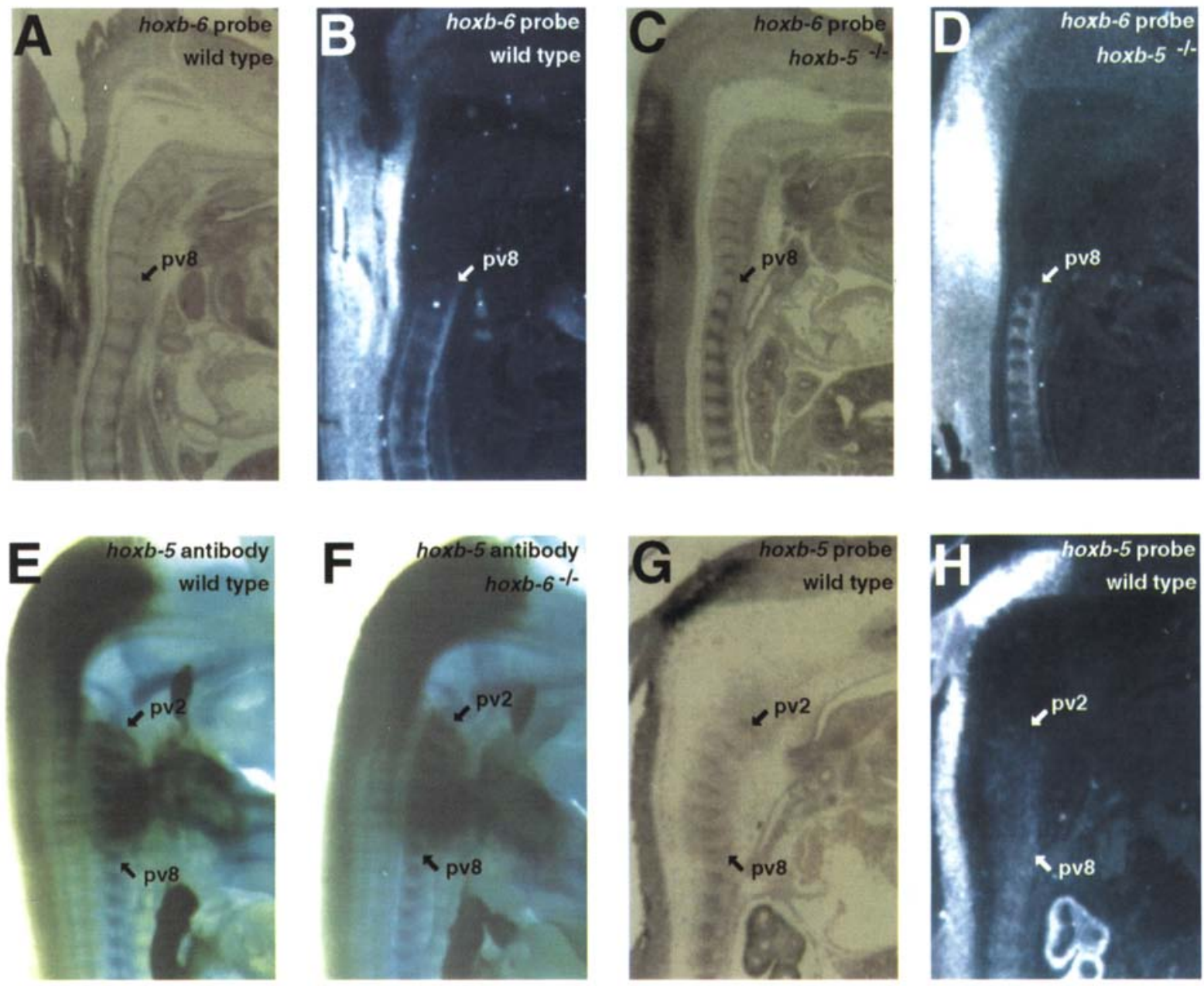

Figure 9. Expression of hoxb-6 and hoxb-5 in wild-type and in hoxb-5 $5^{-}$and hoxb-6 mutant embryos. Parasagittal sections of E12.5 wild-type $(A, B, G, H)$ and hoxb-5- homozygotes $(C, D)$ were hybridized with ${ }^{33}$ P]UTP-labeled hoxb-6 $(A, B, C, D)$ and hoxb-5 $(G, H)$ riboprobes, stained with hematoxylin after autoradiography and viewed with bright-field $(A, C, G)$ and dark-field $(B, D, H)$ illumination. The hoxb-6 probe shows that the anterior expression boundary occurs at pv 8 in both wild-type $(A, B)$, and homozygous hox $b-5^{-}(C, D)$ embryos. The position of pv8 in these embryos was confirmed from its association in separate sections with the first rib primordium (not shown). $(E, F)$ Hemisected wild-type and homozygous hoxb-6- E12.5 embryos were immunostained with anti-hoxb-5 antibody (Wall et al. 1992) and counterstained with alcian blue. No difference in hoxb-5 expression was detected in wild-type and hoxb-6 embryos. The anterior boundary of protein expression (top arrow) occurs at pv2, whereas a posterior boundary is observed at pv8 (bottom arrow). (G,H) The anterior RNA expression boundary for hoxb-5 also occurs at pv2 (top arrow), whereas no posterior boundary is observed at pv8 (bottom arrow).

in humans (McKusick 1992). For instance, unilateral bifid ribs have been observed in man. On the other hand, asymmetries in the lower cervical vertebrae have not been reported, partially because in humans, cervical vertebrae $\mathrm{C} 3-\mathrm{C} 7$ are indistinguishable, perhaps preventing the identification of potential homeotic transformations. Although the vertebral artery normally enters the foramen at $\mathrm{C} 6$, occasionally this position will shift down to C7. This can occur either uni- or bilaterally, but it is unknown whether there is a genetic component to this shifting (Bland and Boushey 1990).

The rostrally shifted shoulder phenotype that we observe in hoxb-5- homozygotes is similar in nature to that of the Sprengel anomaly observed in humans
(McKusick 1992). As seen in humans, the scapula is located in a higher position, with its lower angle turned toward the spine. This can occur either unilaterally or bilaterally. However, in humans, the predominant form of Sprengel anomaly appears to be autosomal dominant, although a recessive form may also exist (Wilson et al. 1971). The Sprengel anomaly is frequently associated with Klippel-Feil syndrome and although we do not see evidence of Klippel-Feil-like cervical fusions in hoxb-5 homozygotes, it is interesting that we observe $\mathrm{C} 2-\mathrm{C} 3$ cervical fusions, similar to type II Klippel-Feil, when the hox $b-5^{-}$mutation is homozygous in a hoxa- $4^{-}$homozygous background (D.E. Rancourt and M.R. Capecchi, unpubl.). 
In summary, we have examined the phenotypic consequences of disrupting hoxb-5 and hoxb-6 in mice. hox $b-5^{-}$mutant mice show an anterior shift in the position of the forelimbs relative to the axial skeleton, arguing that Hox genes are components of the genetic program that specifies limb position in vertebrates, as well as of the programs that regulate the formation of the limb bones themselves. hoxb-6 $6^{-}$homozygotes display defects in the formation of the first and second rib and the first intercostal nerve. Mutations in either hoxb-5 or hox $b-6$ also cause anterior transformation of $\mathrm{C} 6, \mathrm{C} 7$, and T1. Unexpectedly, hox $b-5$ and hox $b-6$ transheterozygotes show the same anterior transformations, suggesting that the two genes interact to specify these cervicothoracic vertebrae. Nonallelic noncomplementation may provide a relatively simple test for identifying genetic interactions between Hox genes mediating the formation of common structures.

\section{Materials and methods}

\section{Generation of hoxb-5 $5^{-}$and hoxb-6 $6^{-}$mice}

Genomic clones surrounding the hoxb-5 and hoxb-6 genes were isolated from a $\mathrm{C} 57 \mathrm{Bl} / 6$ genomic library using ${ }^{32} \mathrm{P}$-labeled oligonucleotides specific for both sequences (Krumlauf et al. 1987, Schughart et al. 1988). The identity of each gene was confirmed by both restriction enzyme mapping and DNA sequence analysis. Individual targeting vectors for hox $b-5$ and hoxb-6 were constructed by the insertion of genomic sequences encompassing each gene between HSV-1 and HSV-2 thymidine kinase genes (Chisaka and Capecchi 1991) and the insertion of $n e o^{r}$ into the first coding exon. pB5neo2TK (Fig. lA) was derived from an 8.9-kb EcoRI genomic fragment in which the MClneo poly(A) cassette (Thomas and Capecchi 1987) was inserted into the BamHI site within the first exon (Krumlauf et al. 1987). Similarly, pB6neo2TK (Fig. 1A) was derived from a $10.1-\mathrm{kb}$ $B a m H I$ genomic fragment that contained an insertion of an RNA polymerase II/neo-poly(A) cassette (Deng et al. 1993) within the EcoRI site of the first exon.

Following linearization, gene targeting vectors were introduced into CC1.2 ES cells by electroporation. Targeted clones were enriched by positive-negative selection (Mansour et al. 1988) and identified by Southern analysis using hybridization probes that flanked the region of either targeting vector (Thomas and Capecchi 1987). The resulting cell lines, $2 \mathrm{c} 6$ and $3 \mathrm{~h} 12$, were used to generate hox $b-6^{-}$and hox $b-5^{-}$mice, respectively, as described previously (Thomas and Capecchi 1990).

\section{DNA analysis}

Genomic DNAs were isolated from ES cells and animals by proteinase $\mathrm{K}$ digestion and phenol-chloroform extraction as described previously (Thomas and Capecchi 1987; Mansour and Capecchi 1993). Southern blot analysis was performed using BiotraceRP nylon (Gelman Scientific) membranes as recommended by the manufacturer. Probes were labeled with ${ }^{32} \mathrm{P}$ by random priming (Pharmacia). The hoxb-6 flanking probe (Fig. $1 F$, probe A) is a $2.5-\mathrm{kb} E c o \mathrm{RI}-B a m H I$ fragment lying immediately 5 ' to genomic sequences used in the hoxb-6 gene targeting vector. The hoxb-5 flanking probe (Fig. $1 \mathrm{~F}$, probe $\mathrm{C}$ ) is a $0.9-\mathrm{kb}$ HindIII-Sau3A fragment $3^{\prime}$ to the sequences used in the hoxb-5 gene targeting vector. An internal probe (Fig. $1 F$, probe $B$ ) is a
1.5- $\mathrm{kb}$ BamHI fragment that was used for genotypic analysis of mice.

Histology, in situ hybridization, and skeletal analysis

Newborn and adult mice were killed by $\mathrm{CO}_{2}$ asphyxiation. Histological sections were collected and stained regressively with hematoxylin and eosin as described /Chisaka and Capecchi 1991). In situ hybridization to E12.5 embryo sections was performed as described previously using ${ }^{33}$ P-labeled riboprobes (Carpenter et al. 1993). The hoxb-6 probe was made from a 330-bp PvuII-EcoRI fragment (Schughart et al. 1988) that was subcloned into SmaI-EcoRI sites of pBluescript SK. The hoxb-5 probe was synthesized from a 450-bp BamHI-HindIII cDNA fragment (Krumlauf et al. 1988) subcloned into pBluescript $\mathrm{KS}(+)$.

Skeletons of newborns were stained with alcian blue 8GX and alizarin red S as described previously (Mansour et al. 1993). Preparations of adult skeletons were similar, except that the carcasses were fixed in $4 \%$ formaldehyde and stained only with alizarin red S in $1 \% \mathrm{KOH}$ (Kostic and Capecchi 1994).

\section{Whole-mount histochemistry and immunohistochemistry}

Mothers bearing mid-gestation embryos were killed by cervical dislocation, and conceptuses were dissected in phosphate-buffered saline (PBS). E12.5 embryos used for immunostaining with anti-hoxb-5 antisera were fixed $2 \mathrm{hr}$ in Bouin's, hemisected, and bleached overnight with several changes of methanol/DMSO/ $30 \% \mathrm{H}_{2} \mathrm{O}_{2}$ (4:1:1) (Wall et al. 1992). All other embryos were pinned (ventral side up) on $4-\mathrm{cm}$ dissecting petri dishes (Carpenter et al. 1993) and fixed in $4 \%$ paraformaldehyde/PBS ( $2 \mathrm{hr}$ ); they were then rinsed in PBS and eviscerated following a ventral midline incision from the umbilical cord to the snout. Carcasses used for immunohistochemistry and lectin histochemistry were bleached in methanol/DMSO/30\% $\mathrm{H}_{2} \mathrm{O}_{2}(4: 1: 1)$.

Whole-mount immunohistochemistry on hemisected E12.5 embryos using anti-hoxb-5 antisera was performed essentially as described by Wall et al. (1992), except that $\mathrm{NiCl}_{2}$ was not included in the peroxidase staining reaction. Similarly, wholemount neurofilament staining using the $2 \mathrm{H} 3$ anti- $155-\mathrm{kD}$ neurofilament monoclonal antibody (Dodd et al. 1988; Chisaka et al. 1992) was conducted using the method of Wall et al. (1992). Following peroxidase staining, embryos were preincubated in cartilage staining buffer (CSB: $70 \%$ methanol, 5\% acetic acid) for $30 \mathrm{~min}$ and then stained with $0.01 \%$ alcian blue $8 \mathrm{GX}$ in CSB for $2 \mathrm{hr}$ at room temperature. Stained carcasses were destained by rinsing thoroughly in CSB, followed by methanol, and cleared in benzoic acid, benzyl benzoate (1:2).

For lectin histochemistry, carcasses were bleached as described above and stained with horseradish peroxidase (HRP)conjugated peanut agglutinin (U.S. Biochemical) at $100 \mu \mathrm{g} / \mathrm{ml}$ using methods identical to those for immunohistochemistry (above). After HRP staining, carcasses were taken through a methanol series to $100 \%$ methanol and cleared as above.

Dye injections were performed essentially as described previously (Carpenter et al. 1993) except that alternating injections of fluorescent carbocyanine dyes (DiI and $\mathrm{DiO}$ ) were limited to the cervical nerves.

\section{Acknowledgments}

We thank M. Allen, S. Barnett, C. Lenz, E. Nakashima, and S. Tamowski for technical assistance. We are grateful to B. Hogan and the Developmental Studies Hybridoma Bank for providing 
us with hoxb-5 and $2 \mathrm{H} 3-155-\mathrm{kd}$ neurofilament antibody, respectively. Dr. E. Carpenter helped with the injection of carbocyanine dyes, and L. Oswald helped with the preparation of the manuscript. D.E.R. was funded by fellowships from the Medical Research Council of Canada and the AMGEN Corporation.

The publication costs of this article were defrayed in part by payment of page charges. This article must therefore be hereby marked "advertisement" in accordance with 18 USC section 1734 solely to indicate this fact.

\section{References}

Akam, M.E. 1987. The molecular basis for metameric pattern in the Drosophila embryo. Development 101: 1-22.

Balling, R., C. Ebensperger, I. Hoffmann, K. Imai, H. Koseki, Y. Mizutani, and J. Wallin. 1993. The genetics of skeletal development. Ann. Genet. 36: 56-62.

Bland, J.H. and D.R. Boushey. 1990. Anatomy and physiology of the cervical spine. Semin. Arthritis Rheum. 20: 1-20.

Braun, T., M.A. Rudnicki, H.-H. Arnold, and R. Jaenisch. 1992. Targeted inactivation of the muscle regulatory gene Myf-5 results in abnormal rib development and perinatal death. Cell 71: 369-382.

Capecchi, M.R. 1989. Altering the genome by homologous recombination. Science 244: 1288-1292.

- 1994. Targeted gene replacement. Sci. Am. 270: 54-61.

Carpenter, E.M., J.M. Goddard, O. Chisaka, N.R. Manley, and M.R. Capecchi. 1993. Loss of Hox-A1 (Hox-1.6) function results in the reorganization of the murine hindbrain. Development 118: 1063-1075.

Chen, J.M. 1952. Studies on the morphogenesis of the mouse sternum II. Experiments on the origin of the sternum and its capacity for self-differentiation in vitro. $J$. Anat. 86: 387401.

- 1953. Studies on the morphogenesis of the mouse sternum. III. Experiments on the closure and segmentation of the sternal bands. J. Anat. 87: 130-149.

Chevalier, A., M. Kieny, A. Mauger, and P. Sengel. 1977. Developmental fate of the somitic mesoderm in the chick embryo. In Vertebrate limb and somite morphogenesis fed. D.A. Ede, J.R. Hinchliffe, and M. Balls|, pp. 421-432. Cambridge University Press, Cambridge, UK.

Chisaka, O. and M.R. Capecchi. 1991. Regionally restricted developmental defects resulting from targeted disruption of the mouse homeobox gene Hox-1.5. Nature 350: 473-479.

Chisaka, O., T.S. Musci, and M.R. Capecchi. 1992. Developmental defects of the ear, cranial nerves and hindbrain resulting from targeted disruption of the mouse homeobox gene Hox-1.6. Nature 355: 516-520.

Christ, B. and J. Whiting. 1992. From somites to vertebral column. Ann. Anat. 174: 23-32.

Condie, B.G. and M.R. Capecchi. 1993. Mice homozygous for a targeted disruption of Hoxd-3 (Hox-4.1) exhibit anterior transformations of the first and second cervical vertebrae, the atlas and the axis. Development 119: 579-595.

1994. Mice with targeted disruptions in the paralogous genes hoxa-3 and hoxd-3 reveal synergistic interactions. $\mathrm{Na}$ ture 370: 304-307.

Davis, A.P. and M.R. Capecchi. 1994. Axial homeosis and appendicular skeleton defects in mice with a targeted disruption of hoxd-11. Development 120: 2187-2198.

Deng, C., K.R. Thomas, and M.R. Capecchi. 1993. Location of crossovers during gene targeting with insertion and replacement vectors. Mol. Cell. Biol. 13: 2134-2140.

Dodd, J., S.B. Morton, D. Karagogeos, M. Yamamoto, and T.M.
Jessell. 1988. Spatial regulation of axonal glycoprotein expression on subsets of embryonic spinal neurons. Neuron 1: 105-116

Dollé, P., A. Dierich, M. LeMeur, T. Schimmang, B. Schuhbaur, P. Chambon, and D. Duboule. 1993. Disruption of the Hoxd13 gene induces localized heterochrony leading to mice with neotenic limbs. Cell 75: 431-441.

Duboule, D. and P. Dollé. 1989. The structural and functional organization of the murine $H o x$ gene family resembles that of Drosophila homeotic genes. EMBO / 8: 1497-1505.

Eid, R., H. Koseki, and K. Schughart. 1993. Analysis of lacZ reporter genes in transgenic embryos suggests the presence of several cis-acting regulatory elements in the murine hoxb-6 gene. Dev. Dyn. 196: 205-216.

Garcia-Fernández, J. and P.W.H. Holland. 1994. Archetypal organization of the amphioxus Hox gene cluster. Nature 370: 563-566.

Gaunt, S.J., P.L. Coletta, D. Pravtcheva, and P.T. Sharpe. 1990. Mouse Hox-3.4: Homeobox sequence and embryonic expression patterns compared with other members of the Hox gene network. Development 109: 329-339.

Gendron-Maguire, M., M. Mallo, M. Zhang, and T. Gridley. 1993. Hoxa-2 mutant mice exhibit homeotic transformation of skeletal elements derived from cranial neural crest. Cell 75: 1317-1331.

Götz, W., G. Fischer, and R. Herken. 1991. Lectin binding pattern in the embryonal and early fetal human vertebral column. Anat. Embryol. 184: 345-353.

Graham, A., N. Papalopulu, and R. Krumlauf. 1989. The murine and Drosophila homeobox gene complexes have common features of organization and expression. Cell 57: 367-378.

Hays, T.S., R. Duering, B. Robertson, M. Prout, and M.T. Fuller. 1989. Interacting proteins identified by genetic interactions: A missense mutation in $\alpha$-tubulin fails to complement alleles of the testis-specific $\beta$-tubulin gene of Drosophila melanogaster. Mol. Cell. Biol. 9: 875-884.

Heitman, J., N.R. Movva, and M.N. Hall. 1991. Targets for cell cycle arrest by the immunosuppressant rapamycin in yeast. Science 253: 905-909.

Holland, P.W.H. and B.L.M. Hogan. 1988. Spatially restricted pattern of expression of the homeobox-containing gene, Hox-2.1 during mouse embryogenesis. Development 102: $159-174$.

Holland, P.W.H., L.Z. Holland, N.A. Williams, and N.D. Holland. 1992. An amphioxus homeobox gene: Sequence conservation, spatial expression during development and insights into vertebrate evolution. Development 116: 653661.

Hunt, P., M. Gulisano, M. Cook, M.-H. Sham, A. Faiella, D. Wilkinson, E. Boncinelli, and R. Krumlauf. 1991. A distinct Hox code for the branchial region of the vertebrate head. Nature 353: 861-864.

Jeannotte, L., M. Lemieux, J. Charron, F. Poirier, and E.J. Robertson. 1993. Specification of axial identity in the mouse: Role of the Hoxa-5 (Hox-1.3) gene. Genes \& Dev. 7: 20852096.

Kappen, C., K. Schughart, and F.H. Ruddle. 1989. Two steps in the evolution of Antennapedia-class vertebrate homeobox genes. Proc. Natl. Acad. Sci. 86: 5459-5463.

Kissinger, C.R., B. Liu, E. Martin-Blanco, T.B. Kornberg, and C.O. Pabo. 1990. Crystal structure of an engrailed homeodomain-DNA complex at $2.8 \AA$ resolution: A framework for understanding homeodomain-DNA interactions. Cell 63: $579-590$.

Kostic, D. and M.R. Capecchi. 1994. Targeted disruptions of the murine hoxa-4 and hoxa- 6 genes result in homeotic trans- 
formations of components of the vertebral column. Mech. Dev. 46: 231-247.

Krumlauf, R., P.W. Holland, J.H. McVey, and B.L.M. Hogan. 1987. Developmental and spatial patterns of expression in the mouse homeobox gene Hox 2.1. Development 99: 603617.

Kuratani, S.C. and N.A. Wall. 1992. Expression of Hox 2.1 protein in restricted populations of neural crest cells and pharyngeal ectoderm. Dev. Dyn. 195: 15-28.

LeMouellic, H., Y. Lallemand, and P. Brulet. 1992. Homeosis in the mouse induced by a null mutation in the Hox-3.1 gene. Cell 69: 251-264.

Lewis, E.B. 1978. A gene complex controlling segmentation in Drosophila. Nature 276: 565-570.

Lufkin, T., A. Dierich, M. LeMeur, M. Mark, and P. Chambon. 1991. Disruption of the Hox-1.6 homeobox gene results in defects in a region corresponding to its rostral domain of expression. Cell 66: 1105-1119.

Mansour, S.L., K.R. Thomas, and M.R. Capecchi. 1988. Disnuption of the proto-oncogene int-2 in mouse embryo-derived stem cells: A general strategy for targeting mutations to nonselectable genes. Nature 336: 348-352.

Mansour, S.L., J.M. Goddard, and M.R. Capecchi. 1993. Mice homozygous for a targeted disruption of the proto-oncogene int-2 have developmental defects in the tail and inner ear. Development 117: 13-28.

Mark, M., T. Lufkin, J.L. Vonesch, E. Ruberte, J.-C. Olivo, P. Dollé, P. Gorry, A. Lumsden, and P. Chambon. 1993. Two rhombomeres are altered in Hoxa-1 mutant mice. Development 119: 319-338.

McKusick, V.A. 1992. Mendelian inheritance in man: Catalogs of autosomal dominant, autosomal recessive, and $X$-linked phenotypes. Johns Hopkins University Press, Baltimore, MD.

Otting, G., Y.Q. Qian, M. Billeter, M. Muller, M. Affolter, W.J. Gehring, and K. Wuthrich. 1990. Protein-DNA contacts in the structure of a homeodomain-DNA complex determined by nuclear magnetic resonance spectroscopy in solution. EMBO J. 9: 3085-3092.

Ramirez-Solis, R., H. Zheng, J. Whiting, R. Krumlauf, and A. Bradley. 1993. Hoxb-4 (Hox-2.6) mutant mice show homeotic transformation of a cervical vertebra and defects in the closure of the sternal rudiments. Cell 73: 279-294.

Rijli, F.M., M. Mark, S. Lakkaraju, A. Dierich, P. Dollé, and P. Chambon. 1993. A homeotic transformation is generated in the rostral branchial region of the head by disruption of Hoxa-2, which acts as a selector gene. Cell 75: 1333-1349.

Rine, J. and I. Herskowitz. 1987. Four genes responsible for a position affect on expression from HML and HMR in Saccharomyces cerevisiae. Genetics 116: 9-22.

Schughart, K., M.F. Utset, A. Awgulewitsch, and F.H. Ruddle. 1988. Structure and expression of Hox-2.2, a murine homeobox-containing gene. Proc. Natl. Acad. Sci. 85: 5582-5586.

Schughart, K., C.J. Bieberich, R. Eid, and F.H. Ruddle. 1991. A regulatory region from the mouse Hox-2.2 promoter directs gene expression into developing limbs. Development 112: $807-811$.

Scott, M.P. 1992. Vertebrate homeobox gene nomenclature. Cell 71: 551-553.

Shen, W., K. Detmer, T.A. Simonitch-Eason, H.J. Lawrence, and C. Largman. 1991. Alternative splicing of the HOX 2.2 homeobox gene in human hematopoietic cells and murine embryonic and adult tissues. Nucleic Acids Res. 19: 539-545.

Small, K.M. and S.S. Potter. 1993. Homeotic transformations and limb defects in Hoxa-11 mutant mice. Genes \& Dev. 7: $2318-2328$
Stearns, T. and D. Botstein. 1988. Unlinked noncomplementation: Isolation of new conditional-lethal mutations in each of the tubulin genes of Saccharomyces cerevisiae. Genetics 119: 249-260.

Thomas, K.R. and M.R. Capecchi. 1987. Site-directed mutagenesis by gene targeting in mouse embryo-derived stem cells. Cell 51: 503-512.

- 1990. Targeted disruption of the murine int-1 protooncogene resulting in severe abnormalities in midbrain and cerebellar development. Nature 346: 847-850.

Varkey, J.P., P.L. Jansma, A.N. Minniti, and S. Ward. 1993. The Caenorhabditis elegans spe-6 gene is required for major sperm protein assembly and shows second site non-complementation with an unlinked deficiency. Genetics 133: 7986.

Verbout, A.J. 1985. The development of the vertebral column. Adv. Anat. Embryol. Cell Biol. 90: 1-122.

Wall, N.A., C.M. Jones, B.L.M. Hogan, and C.V.E. Wright. 1992. Expression and modification of hox-2.1 protein in mouse embryos. Mech. Dev. 37: 111-120.

Wilson, M.G., V.G. Miksity, and N.W. Shinno. 1971. Dominant inheritance of Sprengel's deformity. J. Pediatr. 79: 818-821.

Zappavigna, V., D. Sartori, and F. Mavilio. 1994. Specificity of HOX protein function depends on DNA-protein and protein-protein interactions, both mediated by the homeo domain. Genes \& Dev. 8: 732-744. 


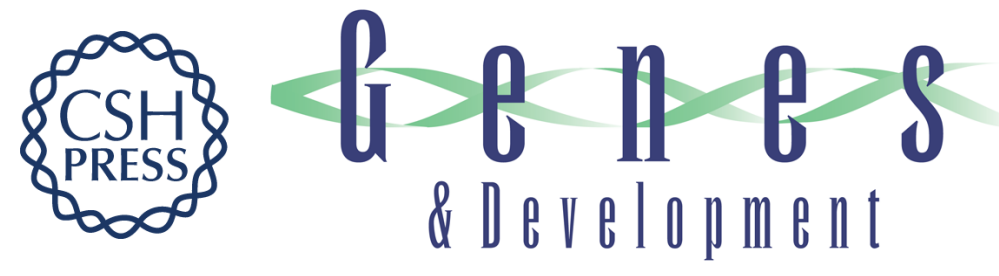

\section{Genetic interaction between hoxb- 5 and hoxb- 6 is revealed by nonallelic noncomplementation.}

D E Rancourt, T Tsuzuki and M R Capecchi

Genes Dev. 1995, 9:

Access the most recent version at doi:10.1101/gad.9.1.108

References This article cites 59 articles, 23 of which can be accessed free at:

http://genesdev.cshlp.org/content/9/1/108.full.html\#ref-list-1

License

Email Alerting

Service

Receive free email alerts when new articles cite this article - sign up in the box at the top right corner of the article or click here.

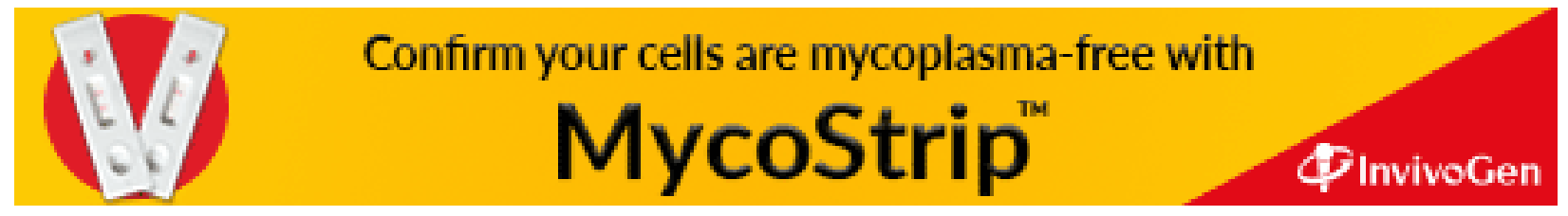

